\title{
Absence of $\mathrm{Cu}-\mathrm{Zn}$ superoxide dismutase BCSOD1 reduces Botrytis cinerea virulence in Arabidopsis and tomato plants, revealing interplay among reactive oxygen species, callose and signalling pathways
}

\author{
JAIME LÓPEZ-CRUZ ${ }^{1}$, ÓSCAR CRESPO-SALVADOR ${ }^{1}$, EMMA FERNÁNDEZ-CRESPO², \\ PILAR GARCÍA-AGUSTIIN² AND CARMEN GONZÁLEZ-BOSCH ${ }^{1, *}$ \\ ${ }^{1}$ Departamento de Bioquímica y Biología Molecular, Universitat de Valencia, Instituto de Agroquímica y Tecnología de Alimentos, CSIC, 46980 Paterna, Valencia, Spain \\ ${ }^{2}$ Grupo de Bioquímica y Biotecnología, Área de Fisiología Vegetal, Departamento de Ciencias Agrarias y del Medio Natural, Escola Superior de Tecnologia i Ciències \\ Experimentals, Universitat Jaume I, 12071 Castellón, Spain
}

\section{SUMMARY}

Plants activate responses against pathogens, including the oxidative burst. Necrotrophic pathogens can produce reactive oxygen species (ROS) that benefit the colonization process. Previously, we have demonstrated that tomato plants challenged with Botrytis cinerea accumulate ROS and callose, together with the induction of genes involved in defence, signalling and oxidative metabolism. Here, we studied the infection phenotype of the $\Delta b c s o d 1$ strain in both tomato and Arabidopsis plants. This mutant lacks bcsod1, which encodes $\mathrm{Cu}-\mathrm{Zn}$ superoxide dismutase (SOD). This enzyme catalyses the conversion of superoxide ion $\left(\mathrm{O}_{2}^{-}\right)$into hydrogen peroxide $\left(\mathrm{H}_{2} \mathrm{O}_{2}\right)$. ROS play a protective role and act as signals in plants. $\Delta b c s o d 1$ displayed reduced virulence compared with wildtype B05.10 in both species. Plants infected with $\Delta b c s o d 1$ accumulated less $\mathrm{H}_{2} \mathrm{O}_{2}$ and more $\mathrm{O}_{2}^{-}$than those infected with $\mathrm{B} 05.10$, which is associated with an increase in the defensive polymer callose. This supports a major role of fungal SOD in $\mathrm{H}_{2} \mathrm{O}_{2}$ production during the plant-pathogen interaction. The early induction of the callose synthase gene PMR4 suggested that changes in ROS altered plant defensive responses at the transcriptional level. The metabolites and genes involved in signalling and in response to oxidative stress were differentially expressed on $\Delta b c s o d 1$ infection, supporting the notion that plants perceive changes in ROS balance and activate defence responses. A higher $\mathrm{O}_{2}^{-} / \mathrm{H}_{2} \mathrm{O}_{2}$ ratio seems to be beneficial for plant protection against this necrotroph. Our results highlight the relevance of callose and the oxylipin 12oxo-phytodienoic acid (OPDA) in the response to changes in the oxidative environment, and clarify the mechanisms that underlie the responses to Botrytis in Arabidopsis and tomato plants.

Keywords: Arabidopsis thaliana, Botrytis cinerea, callose, OPDA, ROS, SOD, Solanum lycopersicum.

\footnotetext{
*Correspondence: Email: carmen.gonzalez@uv.es
}

\section{INTRODUCTION}

In the environment, plants can suffer the invasion of a wide range of pathogens. When an interaction occurs, plants activate their signalling pathways to trigger defence responses to limit pathogen expansion. Plant defence responses include the oxidative burst, an early event considered to be the largest element of resistance to plant diseases (Govrin and Levine, 2000), and which is associated with other mechanisms of resistance. Reactive oxygen species (ROS) are released and lead to the accumulation of harmful radicals, such as singlet oxygen, hydroxyl $\left(\mathrm{OH}^{-}\right)$ and other oxidizing compounds, e.g. hydrogen peroxide $\left(\mathrm{H}_{2} \mathrm{O}_{2}\right)$, which help to limit pathogen advance (de Gara et al., 2003). These molecules can also act as stress signals and trigger programmed cell death (Asselbergh et al., 2008). Phytohormones also play a key role in plant responses to pathogen attack by the signalling and coordination of pathways, but these pathways form part of a complex network that is difficult to interpret. Salicylic acid (SA), jasmonic acid (JA) and ethylene (ET) play an important role in defence responses against phytopathogens. The SA signalling pathway is mainly activated against biotrophic pathogens, whereas JA and ET signalling pathways are associated with resistance against necrotrophic pathogens (Beckers and Spoel, 2006; Zimmerli et al., 2004). However, SA can antagonize JA signalling, and vice versa (Glazebrook, 2005), and the balance between these and other hormones finally determines the outcome of the infection (Caarls et al., 2015; Grant et al., 2009). The pathogen can also manipulate hormone signalling, but the host can attenuate this manipulation. Hence, the fine crosstalk between these pathways generates variable responses according to the challenging pathogen (Glazebrook, 2005; Pieterse et al., 2009; Robert-Seilaniantz et al., 2011). On infection, the penetration site of the pathogen reinforces papilla formation, whose main component is callose (Smart et al., 1986). Callose is a polymer of glucose residues joined by 1,3- $\beta$-D links, which is deposited between the plasma membrane and the inner face of the primary cell wall. Its accumulation occurs against the attack 
of some pathogens and forms part of the hypersensitive response (HR) (Donofrio and Delaney, 2001; Ryals et al., 1996). Papilla formation is an early response that is induced before later responses which may require the transcriptional activation of genes involved in complex signalling pathways (Voigt, 2014). Although callose is not effective against all pathogens, its deposition is a marker of the activation of defence responses (Hauck et al., 2003).

The necrotrophic fungus Botrytis cinerea, responsible for grey mould, causes cell death of its host to aid its colonization. Unlike other plant-pathogenic fungi, Botrytis is able to enter directly into healthy tissue and produce areas of necrotic lesions, which spread rapidly throughout the tissue if plant defences are weak (Williamson et al., 2007). Callose accumulation can hinder the expansion of $B$. cinerea in tomato and Arabidopsis (Finiti et al., 2013; Flors et al., 2007), but the pathogen can exploit SA and JA antagonism as a strategy to cause disease development (El Oirdi et al., 2011). Botrytis also contributes to the oxidative burst on infection and requires plant responses to achieve complete pathogenicity (Heller and Tudzynski, 2011). This has been tested in Arabidopsis plants that lacked HR, where the virulence of Botrytis was diminished (Govrin and Levine, 2000). However, the contribution of both plants and pathogens to ROS production remains unclear. ROS are harmful for the pathogen, but also play a role in the differentiation process in this pathogenic fungus (Viefhues et al., 2014). Botrytis, like other pathogens, possesses multiple enzymes that are involved in ROS-generating systems. One of these is superoxide dismutase (SOD), which belongs to a family of enzymes that neutralize ROS effects by catalysing the conversion of $\mathrm{O}_{2}^{-}$into $\mathrm{H}_{2} \mathrm{O}_{2}$. $\Delta$ bcsod1 is deficient in a gene that encodes the major $\mathrm{Cu}-$ Zn SOD of $B$. cinerea (Rolke et al., 2004). The radial growth and variability in the size of necrotic lesions in French bean leaves are reduced in this strain compared with wild-type (WT) strains (Patel et al., 2008; Rolke et al., 2004).

In this work, we characterized the infection phenotype of the $\Delta$ bcsod1 mutant in Arabidopsis and tomato plants (Solanum lycopersicum cv. Ailsa Craig) compared with the WT strain B05.10. Our results show that the absence of bcsod1 reduces the infectivity of the necrotroph compared with the WT strain in both cultures. On infection, the accumulation of superoxide ion $\left(\mathrm{O}_{2}^{-}\right)$ increases and that of $\mathrm{H}_{2} \mathrm{O}_{2}$ decreases. The imbalance in ROS is associated with increased pathogen-induced callose and with changes in the hormone profile and gene expression. The increase in both 12-0xo-phytodienoic acid (OPDA) accumulation and regulated genes is particularly interesting, confirming the role of this oxylipin in plant responses to pathogens. The differential expression of the genes involved in signalling, defence and the response to oxidative stress demonstrates that plants perceive changes in the ROS environment by the activation of responses that reduce plant susceptibility.

\section{RESULTS}

\section{$\Delta$ bcsod1 mutant shows significantly reduced virulence in Arabidopsis and tomato plants}

Arabidopsis thaliana plants were inoculated with $10^{5} \mathrm{spores} / \mathrm{mL}$ of the B05.10 (WT) or $\Delta b c s o d 1$ strain, and the necrotic lesion areas were determined at 48,72 and $96 \mathrm{~h}$ post-inoculation (hpi). The $\Delta$ bcsod1 mutant showed reduced virulence compared with WT (see Fig. 1A,B). Tomato plants are more susceptible than Arabidopsis plants to $B 05.10$ and were challenged with $5 \times 10^{4}$ spores $/ \mathrm{mL}$ of the B05.10 (WT) or $\Delta b c s o d 1$ strains. Infection tests with the $\Delta$ bcsod1 mutant in young tomato plants showed the same phenotype, with significantly reduced lesions at $72 \mathrm{hpi}$ (Fig. 1C,D).

\section{Lack of bcsod1 alters ROS accumulation on infection}

SOD is an $\mathrm{H}_{2} \mathrm{O}_{2}$-generating enzyme that catalyses the conversion of $\mathrm{O}_{2}^{-}$into $\mathrm{H}_{2} \mathrm{O}_{2}$. We determined the effect of $\Delta b c s o d 1$ infection on ROS in Arabidopsis and tomato plants by analysis of the accumulation of $\mathrm{H}_{2} \mathrm{O}_{2}$ and $\mathrm{O}_{2}^{-}$by $3,3^{\prime}$-diaminobenzidine (DAB) and nitroblue tetrazolium (NBT) staining, respectively. Arabidopsis plants challenged with B05.10 (WT) exhibited brown spots, which are indicative of $\mathrm{H}_{2} \mathrm{O}_{2}$ accumulation, around the infection site and mainly in the central area where most of the mycelium is concentrated. Plants infected with $\Delta b c s o d 1$ presented reduced $\mathrm{H}_{2} \mathrm{O}_{2}$ at both locations at 24, 48 and 72 hpi compared with WT (Fig. 2A). Quantitative analysis showed that $\mathrm{H}_{2} \mathrm{O}_{2}$ accumulation in plants infected with $\Delta b c s o d 1$ was almost two-fold lower than in those infected with B05.10 (Fig. 2B). $\mathrm{O}_{2}^{-}$analysis revealed that the corresponding blue spots accumulated mostly in the central area of the infection site in plants challenged with B05.10. The plants infected with $\Delta b c s o d 1$ showed increased superoxide accumulation at this location at 24, 48 and 72 hpi (Fig. 2C), which was around two-fold greater than in WT (Fig. 2D). Tomato plants inoculated with $\Delta$ bcsod1 exhibited a similar reduction in $\mathrm{H}_{2} \mathrm{O}_{2}$ at the infection site to that observed in Arabidopsis plants, which was associated with an increase in $\mathrm{O}_{2}^{-}$(Fig. 2E, F). These results demonstrate that the absence of fungal SOD alters the oxidative environment in Arabidopsis and tomato plants in association with reduced virulence of $\Delta b c s o d 1$. As $B$. cinerea and the host plant actively produce ROS during infection, we examined whether internal oxidative stress in $\Delta$ bcsod1 before inoculation would reduce fungal virulence and cause the ROS imbalance observed in the infected plants. Quantification of $\mathrm{H}_{2} \mathrm{O}_{2}$ and $\mathrm{O}_{2}^{-}$by $\mathrm{DAB}$ and NBT tests in vitro showed reduced $\mathrm{H}_{2} \mathrm{O}_{2}$ and increased $\mathrm{O}_{2}^{-}$in $\Delta b c s o d 1$ relative to WT (Fig. $3 \mathrm{~A}, \mathrm{~B}$ ). The addition of diphenyleneiodonium (DPI), an inhibitor of flavocytochromes, such as NADPH oxidases, prevented NBT staining, suggesting that superoxide ions are generated enzymatically by flavoenzymes (Fig. 3B). To examine whether inappropriate ROS production of the $\Delta b c s o d 1$ mutant is responsible for its inability to infect, an antioxidant was added in a pathogenicity test. 
A

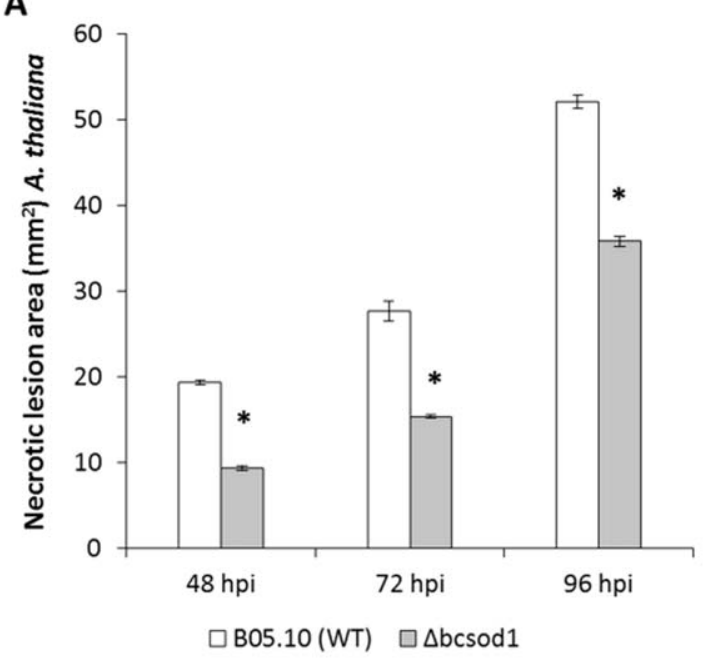

B

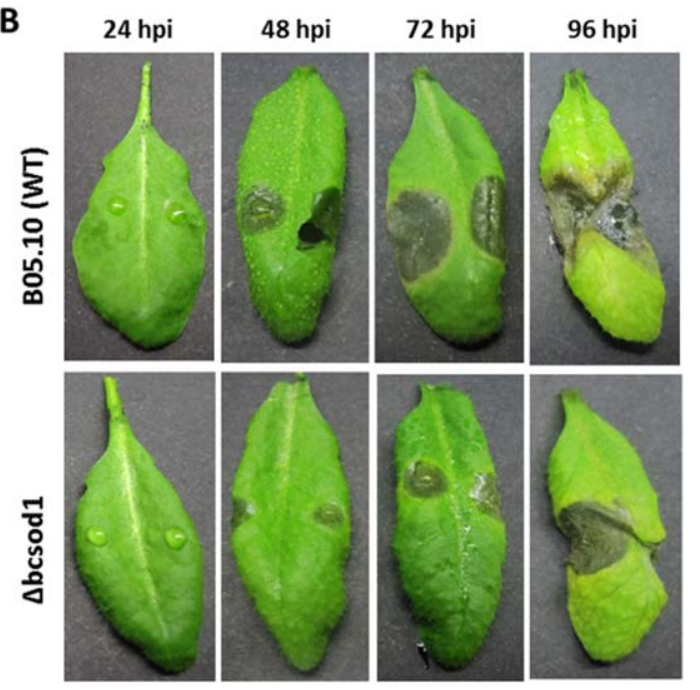

C

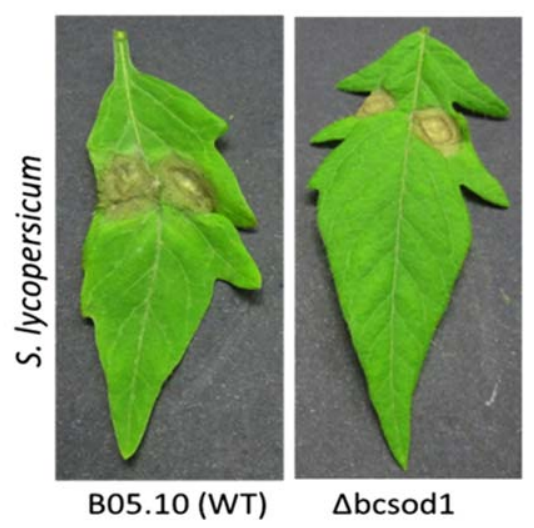

D

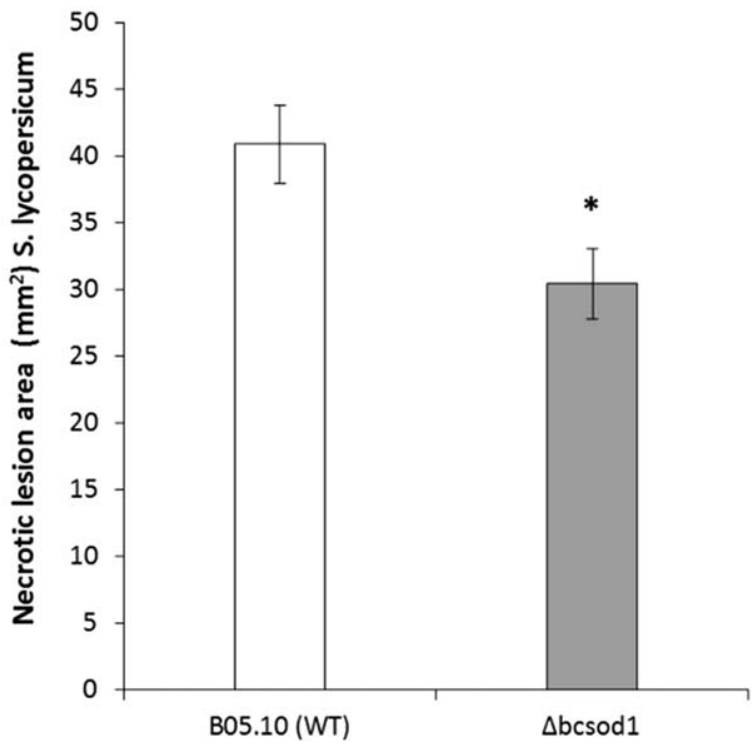

Fig. 1 Arabidopsis and tomato plants infected with $\Delta$ bcsod1 or B05.10 (wild-type, WT). (A) Quantification of the necrotic lesion area measured at 48,72 and $96 \mathrm{~h}$ post-inoculation (hpi) in the leaves of $A$. thaliana. (B) Representative photographs of symptoms at 24, 48, 72 and 96 hpi of B05.10 (WT) and $\Delta b c s o d 1$ strains in the leaves of $A$. thaliana plants. (C) Representative photographs of symptoms at $72 \mathrm{hpi}$ of B05.10 (WT) and $\Delta b c s o d 1$ strains in the leaves of Solanum lycopersicum plants. (D) Quantification of the necrotic lesion area measured at $72 \mathrm{hpi}$ in the leaves of $S$. lycopersicum plants. Bars are the means of three independent experiments \pm standard deviation (SD) $(n=18)$. Asterisks indicate statistically significant differences $(P<0.05$, unpaired $t$-test, two-tailed).

Previously, this experimental approach has demonstrated the role of the thioredoxin system in the pathogenesis of $B$. cinerea (Viefhues et al., 2014).

The addition of the antioxidant ascorbic acid (AA) to the spore suspension prior to inoculation decreased the infection rate of B05.10, as expected, but did not rescue the WT infection phenotype in $\triangle b c s o d 1$ (Fig. $3 C, D)$. Under these conditions, ROS accumulation was reduced significantly, demonstrating its contribution to the infection process. The absence of infection in the presence of dithiothreitol (DTT) confirms that ROS are crucial in this plant- pathogen interaction (Fig. 3D). Even in the reducing environment of ascorbate, $\triangle b c s o d 1$ infection still produced a ROS imbalance in relation to $B 05.10$, with increased superoxide accumulation and reduced peroxide (Fig. 3E-G).

\section{Lack of bcsod1 increases pathogen-induced callose accumulation}

Callose is a plant polysaccharide which is considered to be a good marker of the stress response and a physical barrier against 
A

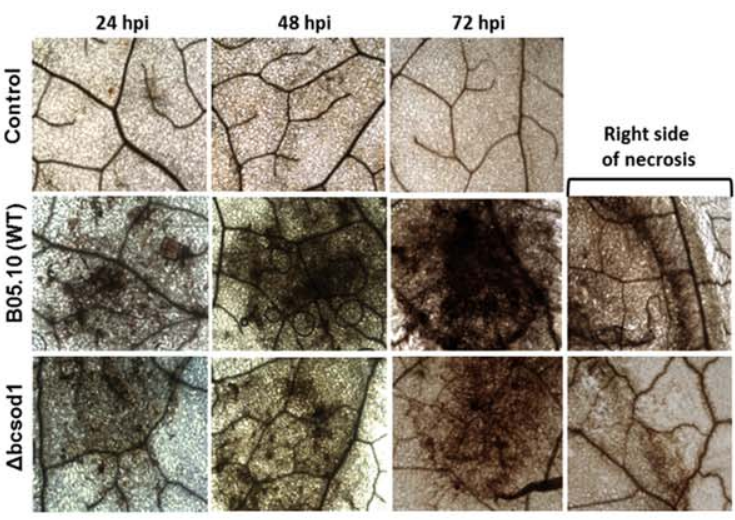

C

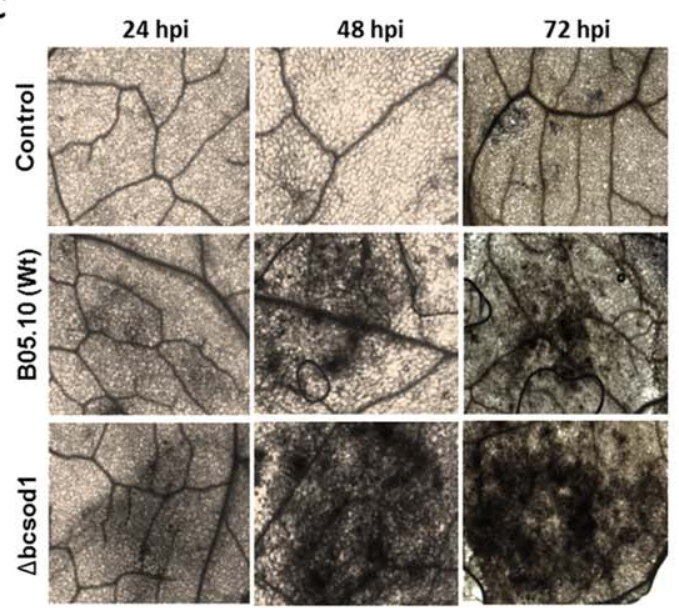

E

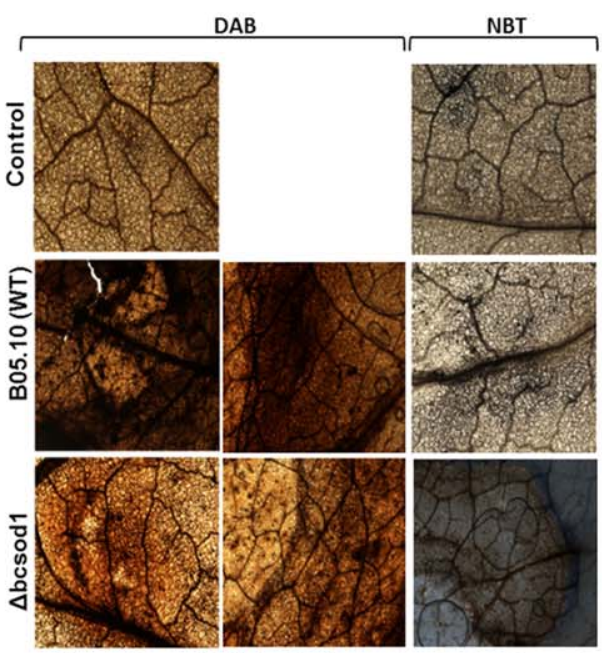

B

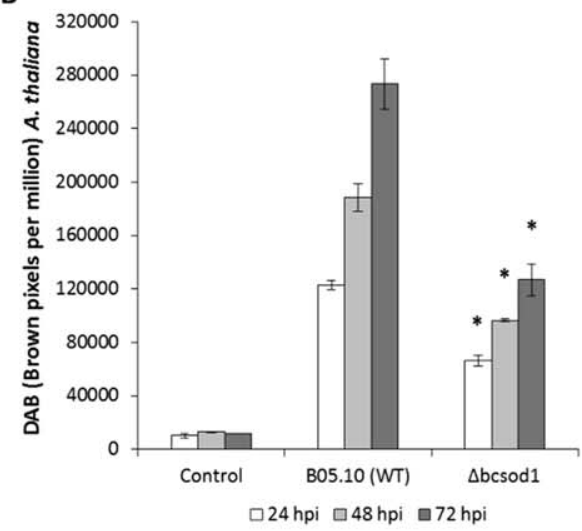

D

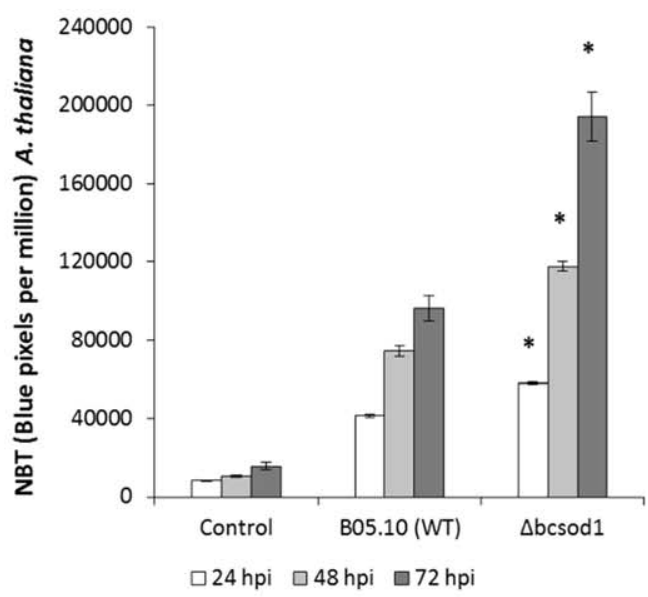

$\mathbf{F}$

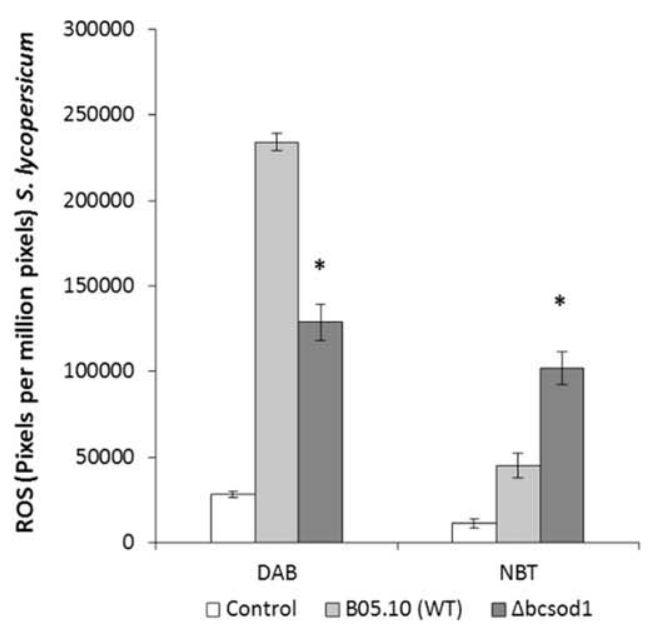

Fig. 2 Hydrogen peroxide $\left(\mathrm{H}_{2} \mathrm{O}_{2}\right)$ and superoxide ion $\left(\mathrm{O}_{2}^{-}\right)$accumulation in Arabidopsis and tomato plants inoculated with $\Delta$ bcsod1 or B05.10 (wild-type, WT). The production of $\mathrm{H}_{2} \mathrm{O}_{2}$ and $\mathrm{O}_{2}^{-}$was viewed by 3,3'-diaminobenzidine (DAB) and nitroblue tetrazolium (NBT) staining, respectively. (A) Representative photographs of $\mathrm{H}_{2} \mathrm{O}_{2}$ accumulation by DAB staining in Arabidopsis leaves at 24, 48 and $72 \mathrm{~h}$ post-inoculation (hpi). (B) Quantification of $\mathrm{H}_{2} \mathrm{O}_{2}$ by digital image analysis at each time point. (C) Representative photographs of $\mathrm{O}_{2}^{-}$accumulation by NBT staining in Arabidopsis leaves at 24,48 and $72 \mathrm{hpi}$. (D) Quantification of $\mathrm{O}_{2}^{-}$by digital image analysis at each time point. $(E, F)$ Representative photographs and quantification of both $\mathrm{H}_{2} \mathrm{O}_{2}$ and $\mathrm{O}_{2}^{-}$accumulation by DAB and NBT staining, respectively, at 72 hpi in tomato leaves. The average of the brown $\left(\mathrm{H}_{2} \mathrm{O}_{2}\right)$ or blue $\left(\mathrm{O}_{2}^{-}\right)$pixels versus the total pixels of 10 photographs per plant was calculated. ROS, reactive oxygen species. The data shown are the means of three independent experiments \pm standard deviation $(S D)(n=18)$. Asterisks indicate statistically significant differences $(P<0.05$, unpaired $t$-test, two-tailed). 
A

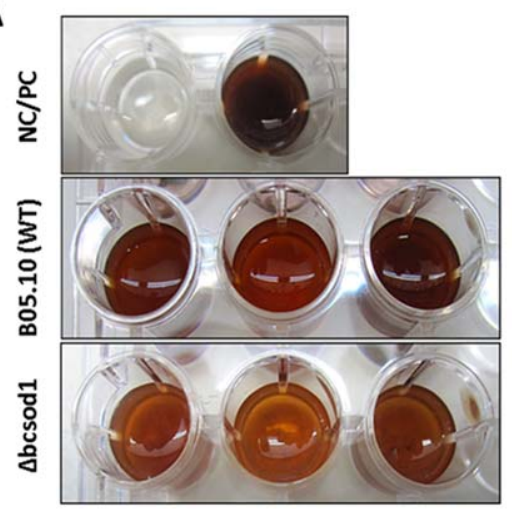

\section{C}

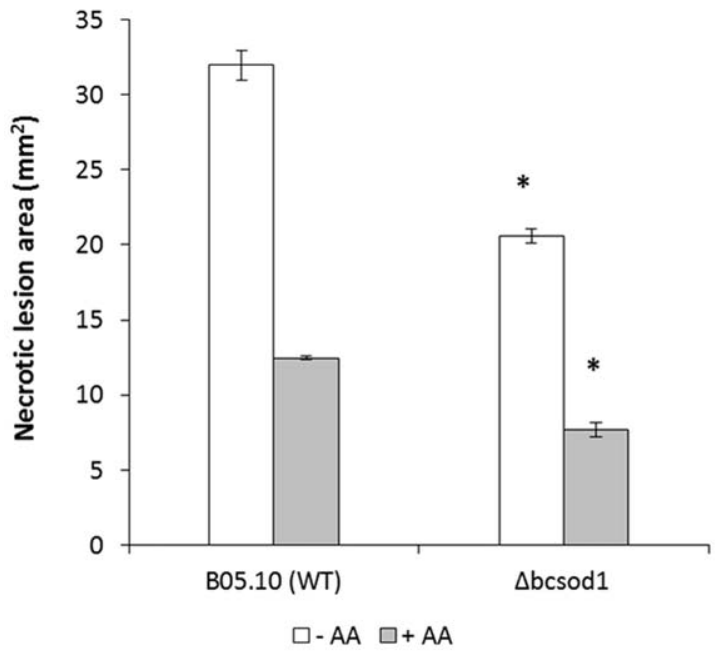

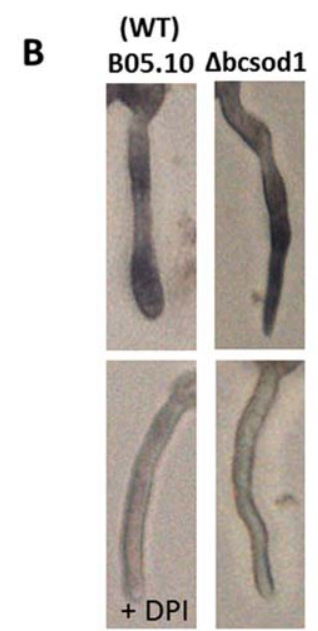

D

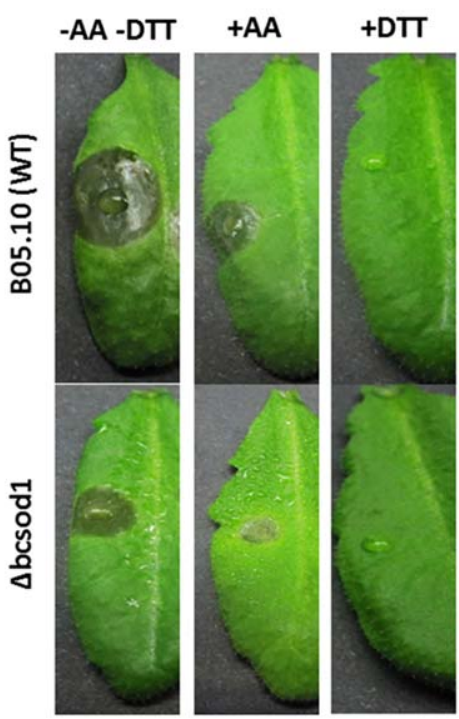

Fig. 3 Hydrogen peroxide $\left(\mathrm{H}_{2} \mathrm{O}_{2}\right)$ and superoxide ion $\left(\mathrm{O}_{2}^{-}\right)$production and influence of the antioxidants ascorbic acid (AA) and dithiothreitol (DTT) on Arabidopsis plants inoculated with $\Delta b c s o d 1$ or B05.10 (wild-type, WT). (A) 3,3'-Diaminobenzidine (DAB) test in a microwell plate to analyse $\mathrm{H}_{2} \mathrm{O}_{2}$ production of both $\Delta b c 50 d 1$ and B05.10 (WT). Twenty-five milligrams of fresh mycelium were weighed and $1 \mathrm{~mL}$ of DAB solution was added. Incubation took place for $2 \mathrm{~h}$ in the dark. NC, negative control, DAB solution $+1 \mu \mathrm{L} \mathrm{H} \mathrm{H}_{2} ; \mathrm{PC}$, positive control, DAB solution $+1 \mu \mathrm{L} \mathrm{H}_{2} \mathrm{O}_{2}+1 \mu \mathrm{L}$ horseradish peroxidase. (B) Superoxide detection in germinated spores (suspension of $10^{5}$ spores $/ \mathrm{mL}$ ) of Botrytis cinerea $\Delta b c s o d 1$ and B05.10 (WT) by nitroblue tetrazolium (NBT) staining. As a control, diphenyleneiodonium (DPI) $(50 \mu \mathrm{m})$ was added prior to NBT supplementation. (C) In planta infection assay with AA of $\Delta b c s o d 1$ and WT. Conidial suspensions of $10^{5} \mathrm{spores} / \mathrm{mL}$ were supplemented with $5 \mathrm{~g}$ of AA per litre prior to inoculation. Quantification of the necrotic lesion area at $72 \mathrm{~h}$ post-inoculation (hpi). (D) Representative photographs of the infection assay in Arabidopsis plants with AA and DTT at $72 \mathrm{hpi}$. Conidial suspensions of $10^{5} \mathrm{spores} / \mathrm{mL}$ were supplemented with $750 \mu \mathrm{m}$ of DTT prior to infection. (E) Representative photographs of both $\mathrm{H}_{2} \mathrm{O}_{2}$ and $\mathrm{O}_{2}^{-}$accumulation by DAB and NBT staining, respectively, at 72 hpi in Arabidopsis leaves inoculated with spores supplemented with $A A$ at 72 hpi. $(F, G)$ Quantification of $\mathrm{H}_{2} \mathrm{O}_{2}$ and $\mathrm{O}_{2}^{-}$by digital image analysis in Arabidopsis leaves inoculated with spores supplemented with $\mathrm{AA}$ at $72 \mathrm{hpi}$. The data shown are the means of three independent experiments \pm standard deviation (SD) $(n=18)$. Asterisks indicate statistically significant differences $(P<0.05$, unpaired $t$-test, two-tailed).

several pathogens (Ellinger et al., 2013; Hauck et al., 2003; Vicedo et al., 2009). Aniline blue staining demonstrated increased fungalinduced callose accumulation in $\Delta b c s o d 1$-infected Arabidopsis plants at 72 hpi compared with the plants infected with B05.10 (WT) (Fig. 4A, I). Callose deposits showed a central core region in which most of the polymer accumulated, surrounded by a layer of callose on the edge of the lesions (Fig. 4A, II/III). When we compared $\Delta b c s o d 1$ and B05.10 infection, we determined an evident increase in callose on the border, but also in the core region at 72 hpi (Fig. 4A, III). Tomato plants infected with $\Delta b c$ csod1 also showed increased pathogen-induced callose compared with plants infected with WT (Fig. 4B, I). Polymer deposits showed a central 


\section{E}

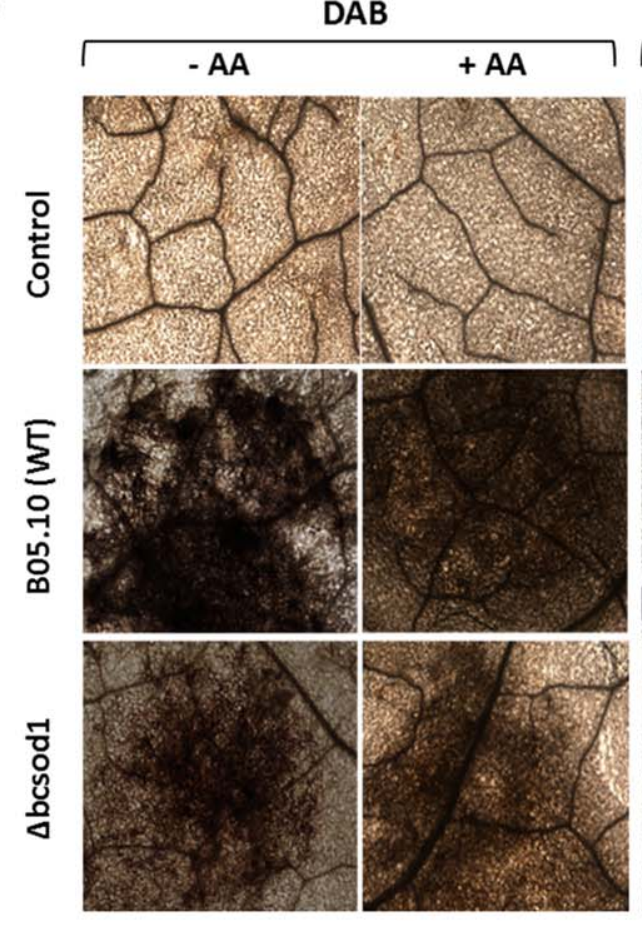

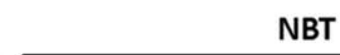

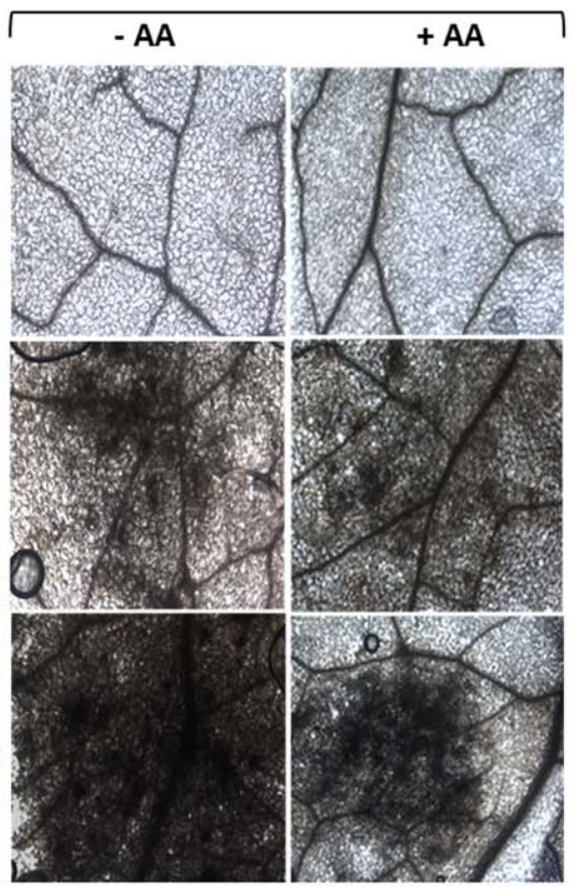

G

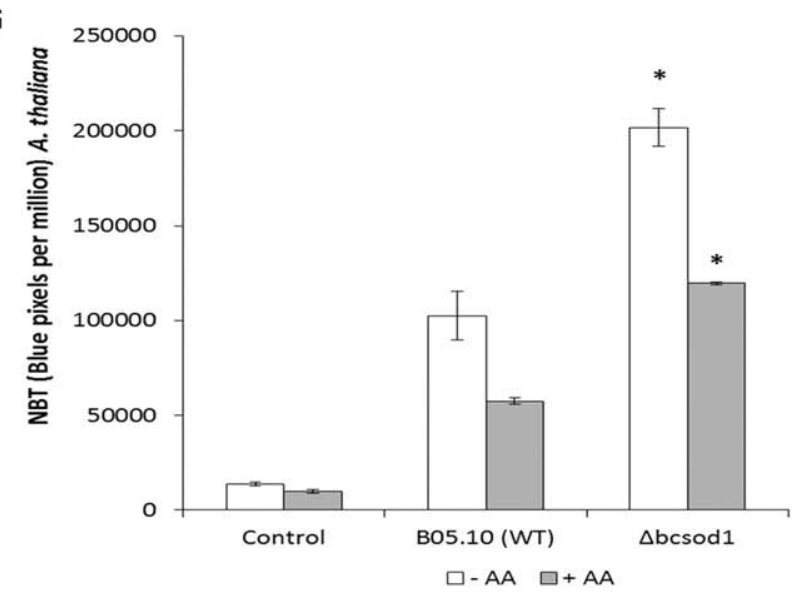

the transcript levels of the PMR4 gene were induced significantly following fungal (B05.10) inoculation at all the analysed time points, showing a significant increase at $24 \mathrm{hpi}$ in $\Delta b c s o d 1$ mutant-infected plants (Fig. 4A,B, IV).

\section{Changes in metabolite accumulation and gene expression of plants challenged with the $\Delta$ bcsod 1 mutant}

To determine the impact of the absence of bcsod 1 on the plant basal response, we analysed the accumulation of the main phytohormones and phenolic compounds of Arabidopsis and tomato 
A

(I)

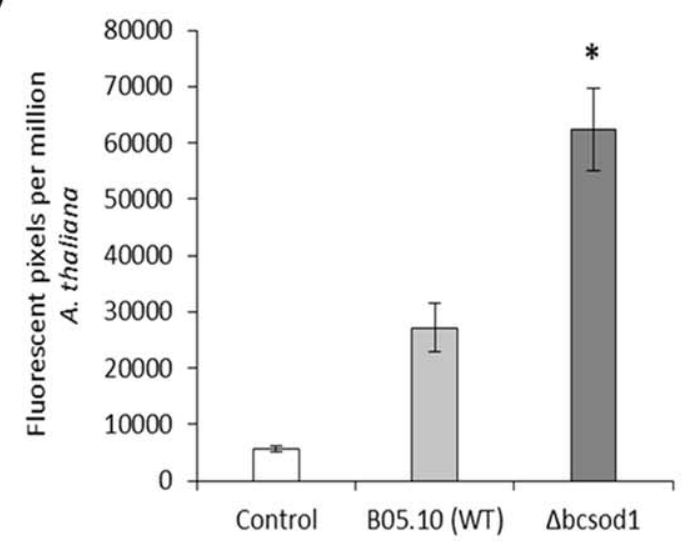

(II)

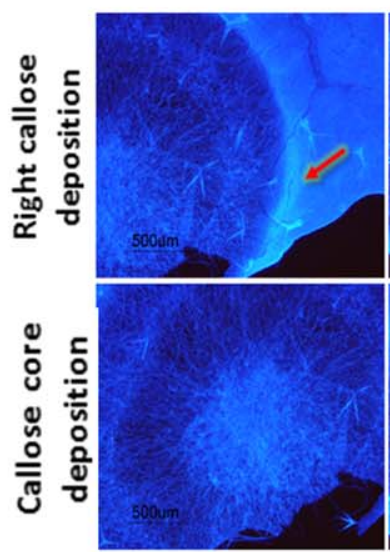

B05.10 (WT)
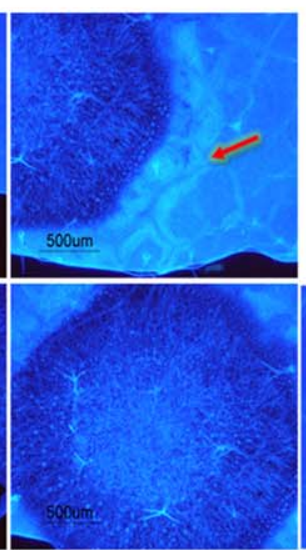

$\Delta$ bcsod1

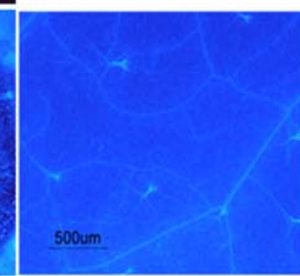

Control
(III)

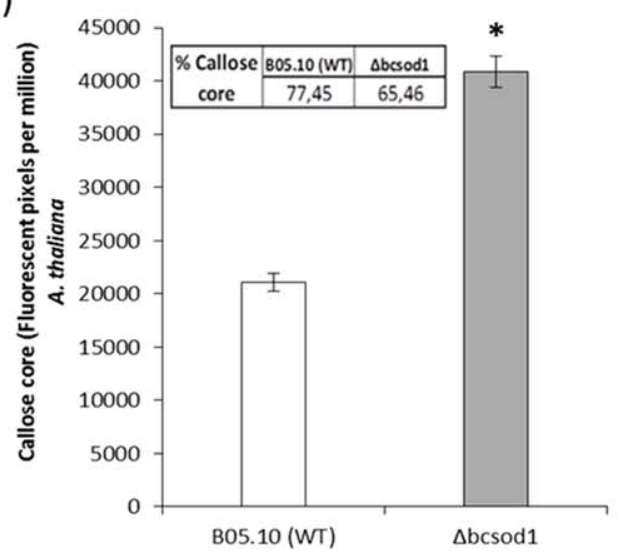

(IV)

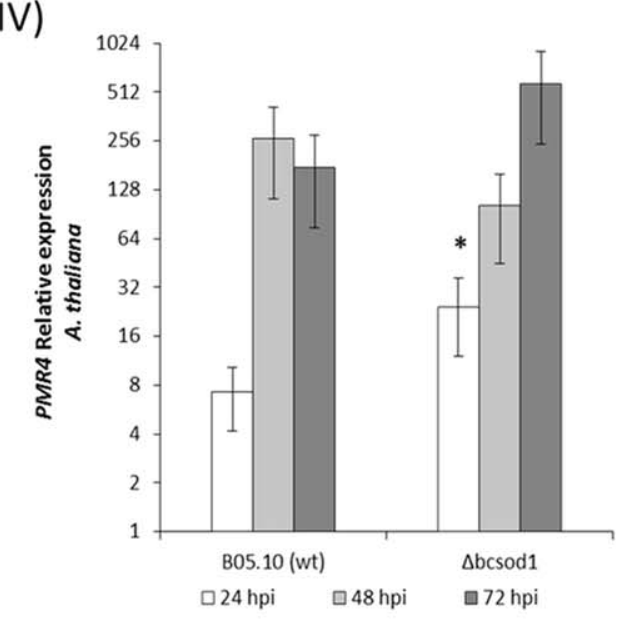

Fig. 4 Callose deposition and PMR4 expression in Arabidopsis and tomato plants at $72 \mathrm{~h}$ post-inoculation (hpi) with $\Delta$ bcsod1 or B05.10 (wild-type, WT). (A, B) I, Quantification of callose visualized by aniline blue staining, performed by the determination of the number of fluorescent pixels per million pixels corresponding to pathogen-induced callose on digital photographs of infected leaf areas. II, Representative photographs of callose staining at 72 hpi with bcsod1 or B05.10 in Arabidopsis and tomato leaves. Arrows indicate deposition of callose on the edge of the lesion. III, Quantification of callose core deposition in the infection area by digital image analysis in Arabidopsis and tomato leaves. Table shows the percentage of callose deposition in the core relative to the total deposition. IV, Relative expression of the callose gene PMR4 at 24, 48 and $72 \mathrm{hpi}$. Values presented are the means of three independent experiments \pm standard deviation (SD) ( $n=18$ ). Asterisks indicate statistically significant differences $(P<0.05$, unpaired $t$-test, two-tailed).

plants infected with the $\Delta b c s o d 1$ mutant and B05.10 (WT) (Fig. $5 A-G)$. The analysis was performed by high-performance liquid chromatography (HPLC) coupled to a mass spectrometer and consisted of the simultaneous determination of the following compounds in the same sample [abscisic acid (ABA), SA, jasmonic acid-isoleucine (JA-lle), JA, OPDA, caffeic acid and ferulic acid] at the following time points $(0,24,48$ and $72 \mathrm{hpi})$ after infection with B05.10 or $\Delta$ bcsod1 and without infection (mock).

The JA-lle content increased at 48 hpi in Arabidopsis plants infected with the $\Delta b c s o d 1$ mutant compared with those inoculated with B05.10 (Fig. 5). These plants also presented a signifi- cant increase in ABA and OPDA at $72 \mathrm{hpi}$, together with decreased free SA content, compared with those infected with WT (Fig. 5). Interestingly, caffeic acid accumulated rapidly on $\Delta b c s o d 1$ mutant infection (24 hpi) and remained stable up to $72 \mathrm{hpi}$ (Fig. 5). This acid is a precursor of lignin and is a component of the papilla (Soylu et al., 2005; Vicedo et al., 2009). The analysis of tomato plants infected with the $\Delta b c s o d 1$ mutant showed a similar alteration of the hormone and metabolite profile with a few differences (Fig. 6A-G). As in Arabidopsis, the OPDA and ABA content increased significantly at $72 \mathrm{hpi}$ and the amount of SA decreased at this time point. However, the JA-lle content remained 


\section{B}

(I)

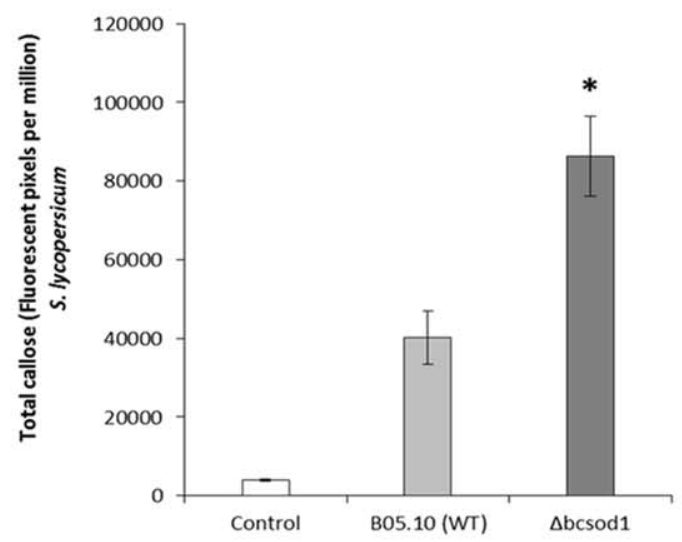

(II)

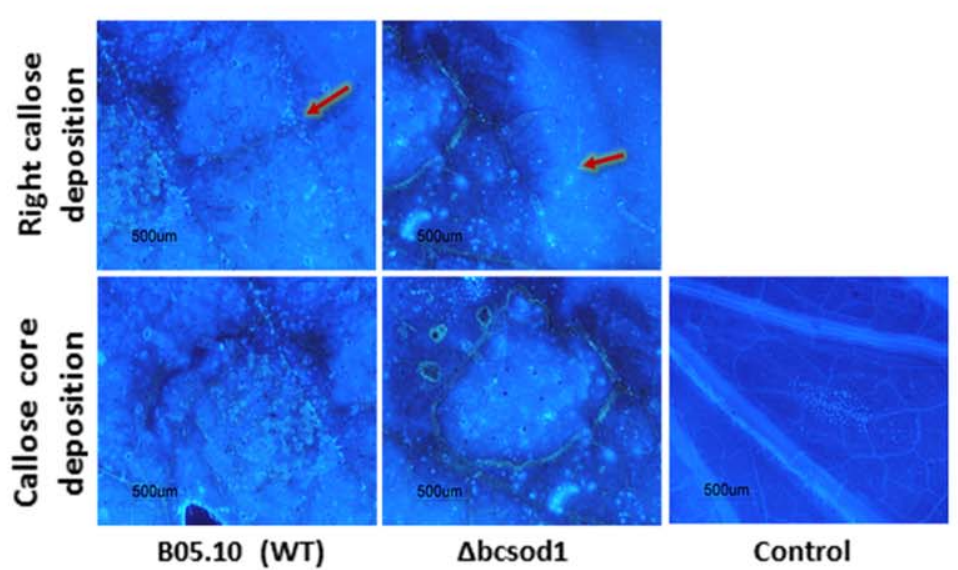

(III)

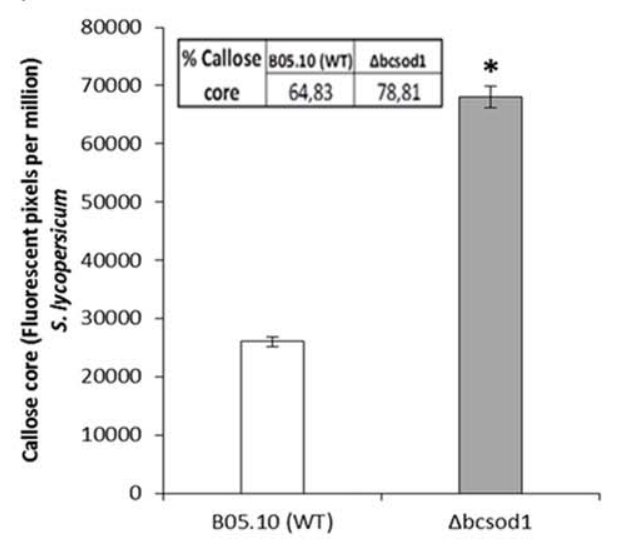

(IV)

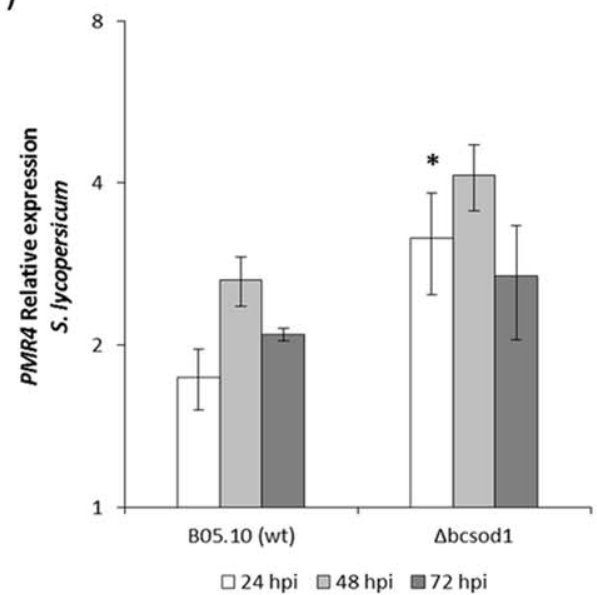

Fig. 4 Continued.

unchanged and the increase in ferulic acid was delayed in tomato plants on $\Delta b c s o d 1$ infection compared with plants infected with B05.10 at 72 hpi (Fig. 6).

To verify the connection between the absence of bcsod1 and the activation of signalling pathways, we analysed the expression patterns of the marker genes for SA (ICS1, PR1, PR2), JA/ET (PDF1.2), JA (VSP1) and OPDA (HSP17.4, HsfA2) by RT-qPCR in Arabidopsis plants infected with $\Delta b c s o d 1$ and $\mathrm{B} 05.10$ at 24,48 and 72 hpi (Fig. 7A-J).

As expected, B05.10 infection significantly induced PDF1.2 expression, a resistance marker to necrotrophs, at all time points in Arabidopsis plants. Infection with $\Delta$ bcsod1 remarkably increased PDF1.2 expression (Fig. 7) at $24 \mathrm{hpi}$, which correlated with the activation of the JA signalling pathway and reduced virulence of the mutant. The remarkable increase in OPDA accumulation on $\Delta b c s o d 1$ infection correlated with the early induction at $24 \mathrm{hpi}$ of the two genes regulated by this oxylipin: HSP17.4 and HsfA2 (Masuda et al., 2014; Sham et al., 2014) (Fig. 7). ICS1 expression increased slightly at $72 \mathrm{hpi}$ in plants infected with $\Delta b c s o d 1$ compared with WT, despite the slight reduction observed in free SA levels (Fig. 7). B05.10 infection significantly induced PR1 expression in Arabidopsis, with similar observations in $\Delta b c s o d 1$-infected plants (Fig. 7). However, PR2 expression increased in plants infected with $\Delta b c s o d 1$ at 24 and $72 \mathrm{hpi} \mathrm{com-}$ pared with those inoculated with B05.10 (Fig. 7).

We also analysed the marker genes for SA (PR1, PR2), JA (LoxD), other oxylipins (DES) and OPDA (HsfA2) by RT-qPCR in tomato plants infected with $\Delta b c s o d 1$ and B05.10 at 24, 48 and 72 hpi (Fig. 8A-H). The absence of the bcsod1 gene significantly reduced LoxD expression, a gene marker of JA signalling, at 72 hpi, but increased DES accumulation at this time point, which is involved in other oxylipin synthesis (Itoh and Howe, 2001). The expression of HsfA2, a marker gene of OPDA in tomato, increased at all time points in plants challenged with $\Delta b c s o d 1$ versus those inoculated with WT (Fig. 8). These changes at the transcriptional level correlate with significant 

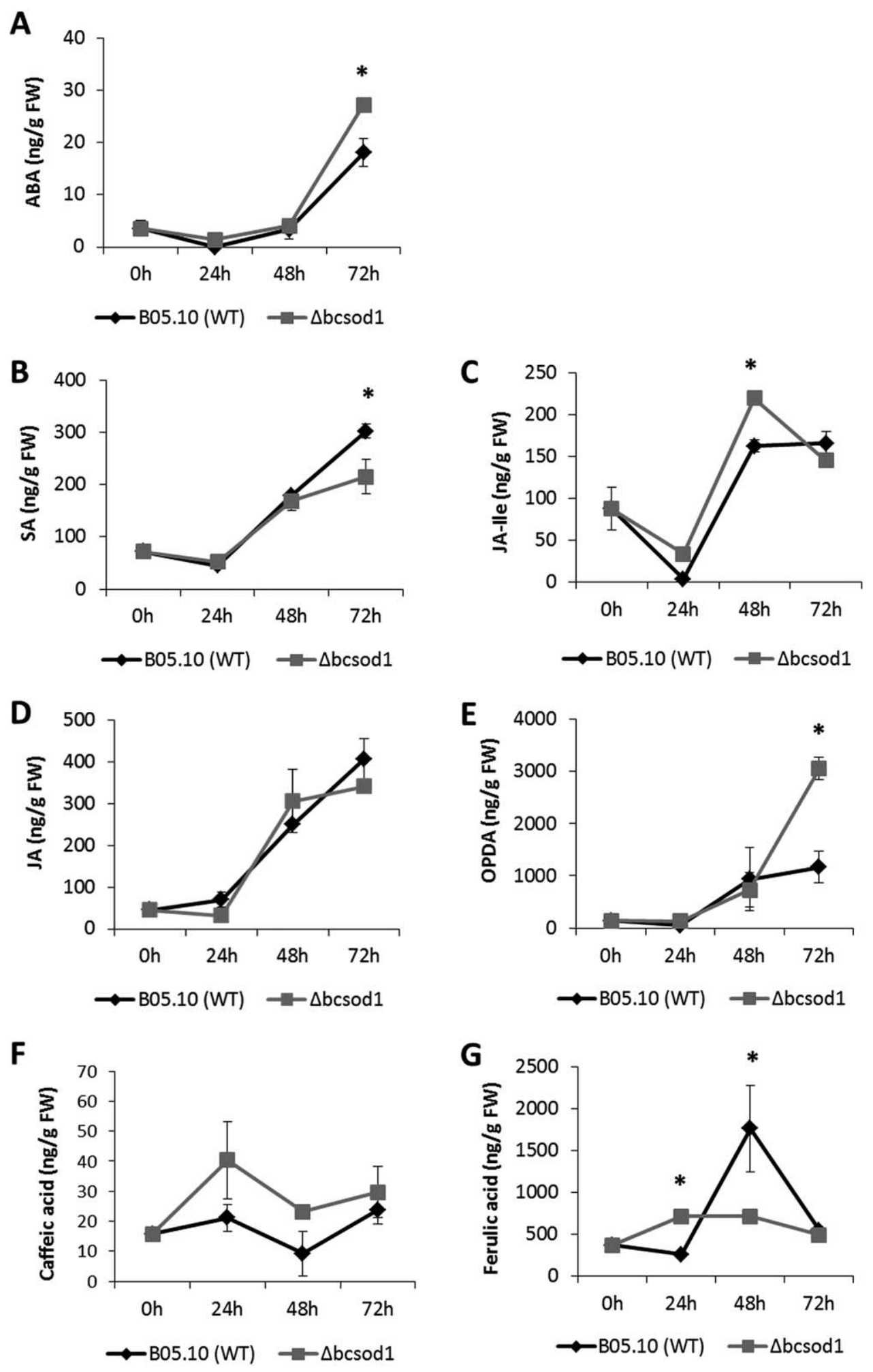
Fig. 5 Hormone and metabolite analysis of Arabidopsis plants not inoculated (mock) and inoculated with $\Delta b c s o d 1$ or B05.10 (wild- type, WT). (A-G) Abscisic acid $(A B A)$, salicylic acid $(S A)$, jasmonic acid-isoleucine (JA-lle), jasmonic acid (JA), 12-oxo- phytodienoic acid (OPDA), caffeic acid and ferulic acid levels determined by high-performance liquid chromatography-mass spectrometry (HPLC-MS) in leaves collected at 0, 24, 48 and $72 \mathrm{~h}$ post-inoculation (hpi). Bars are the means of three independent experiments \pm standard deviation (SD) $(n=12)$. Asterisks indicate statistically significant differences between plants infected with B05.10 (WT) and $\Delta b c s o d 1$ strains at each time point $(P<0.05$, unpaired $t$-test, two-tailed).

OPDA accumulation and unaltered accumulation of JA-lle on $\triangle b c s o d 1$ infection. In tomato, $P R 1$ expression increased significantly in response to Botrytis, as reported previously (Finiti et al., 2014; Vicedo et al., 2009), and was reinforced in plants infected with $\Delta b c s o d 1$ at $72 \mathrm{hpi}$ (Fig. 8). PR2, however, decreased slightly (Fig. 8), which indicates that the SAdependent pathway is also altered in tomato on infection with $\Delta b c s o d 1$, but no changes in free SA accumulation were found. 
Fig. 6 Hormone and metabolite analysis of tomato plants not inoculated (mock) and inoculated with $\Delta b c s o d 1$ or B05.10 (wildtype, WT). (A-G) Abscisic acid (ABA), salicylic acid (SA), jasmonic acid-isoleucine (JA-lle), jasmonic acid (JA), 12-oxo-phytodienoic acid (OPDA), caffeic acid and ferulic acid levels determined by high-performance liquid chromatography-mass spectrometry (HPLCMS) in leaves collected at $0,24,48$ and $72 \mathrm{~h}$ post-inoculation (hpi). Bars are the means of three independent experiments \pm standard deviation (SD) ( $n=12)$. Asterisks indicate statistically significant differences between plants infected with B05.10 (WT) and $\Delta b c s o d 1$ strains at each time point $(P<0.05$, unpaired $t$-test, two-tailed).

We also analysed the expression of the genes related to oxidative stress. No changes in GST6, a gene related to ROS detoxification, occurred in Arabidopsis and tomato plants infected with $\Delta$ bcsod1 compared with B05.10 (Figs 7 and 8). However, WRKY53 and WRKY33, which encode transcription factors regulated by oxidative stress, showed a differential expression in plants challenged with Botrytis that lacked bcsod1. WRKY53 increased significantly at 48 and 72 hpi in Arabidopsis, but no
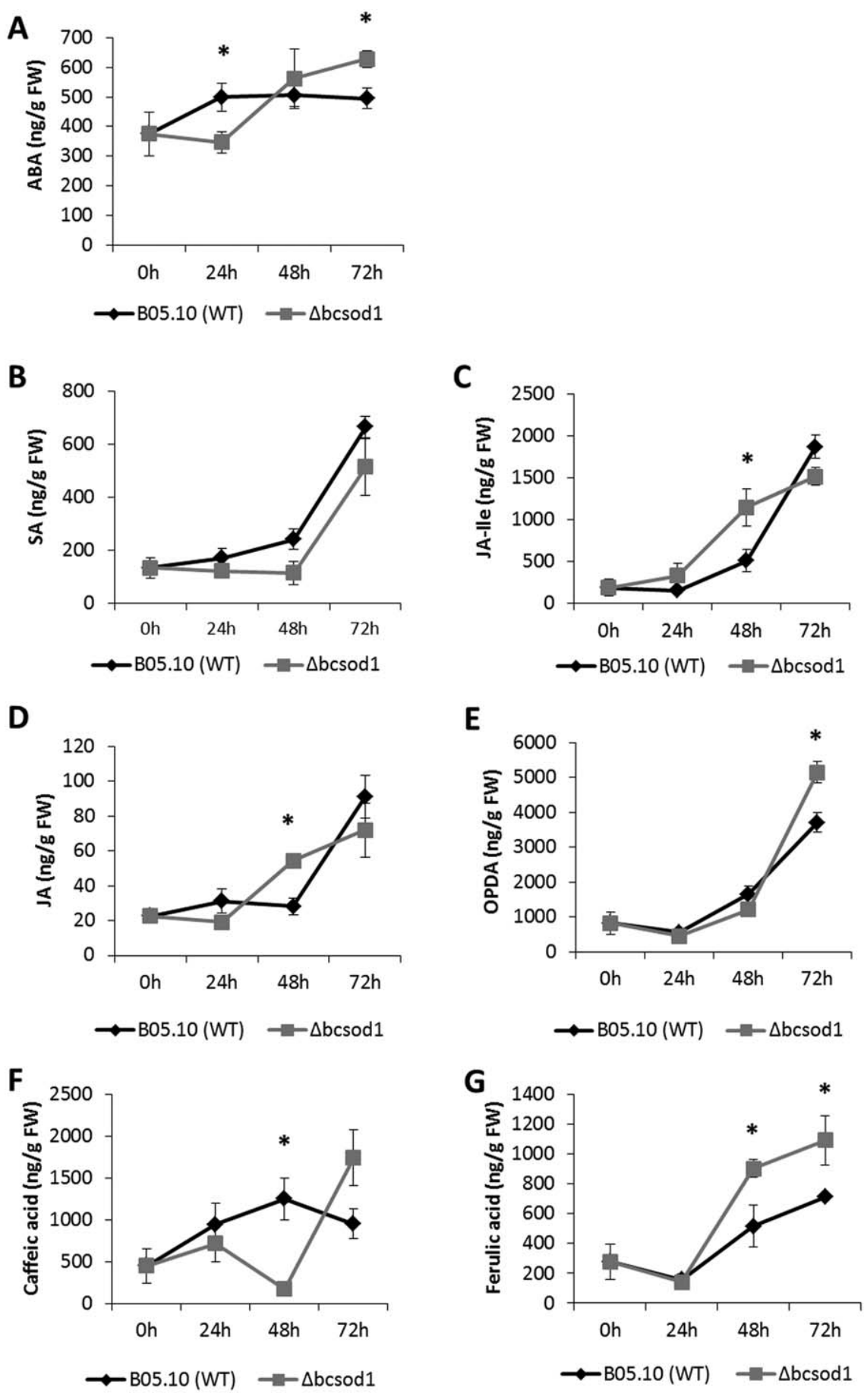

changes in WRKY33 occurred (Fig. 7), whereas both transcripts were reduced significantly in tomato plants inoculated with $\Delta b c s o d 1$ (Fig. 8).

\section{DISCUSSION}

The oxidative burst and ROS accumulation are critical factors in $B$. cinerea infection, but the contribution of ROS to the plant- 
A

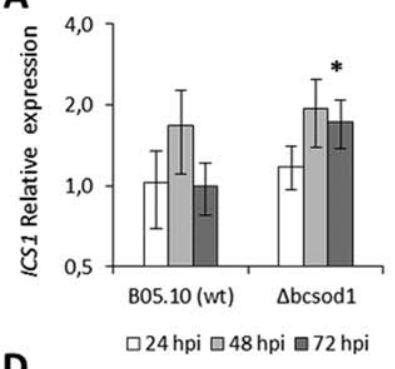

D
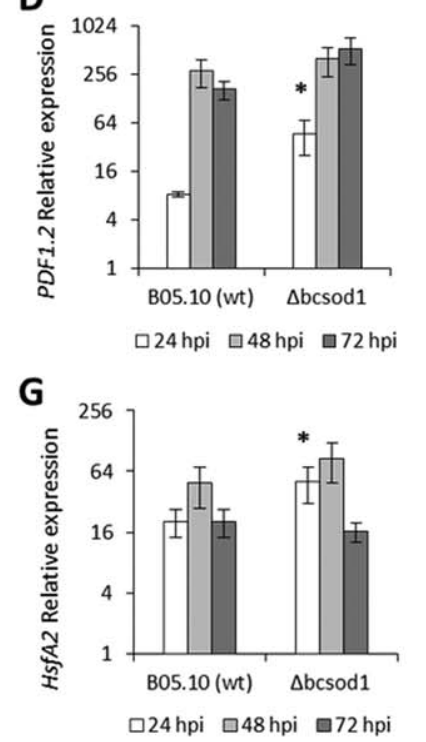

B

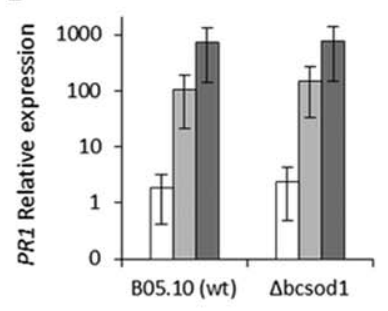

$\mathbf{E}$

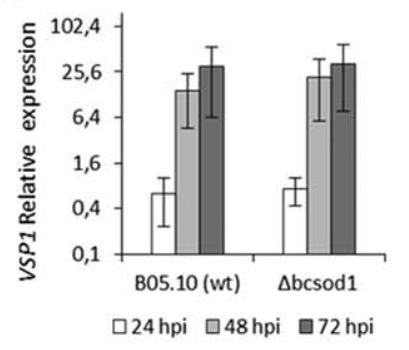

H

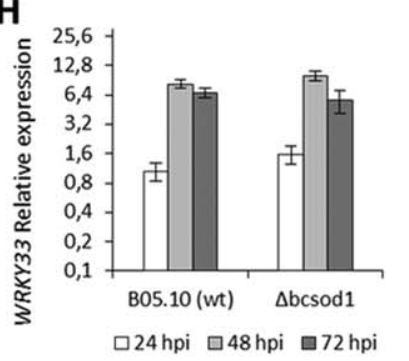

C

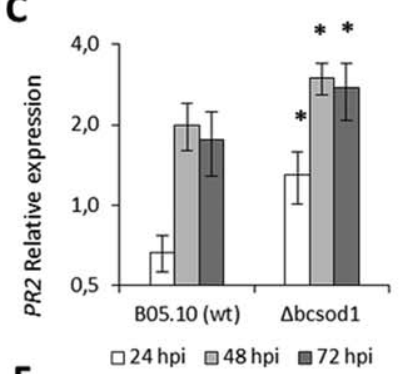

$\mathbf{F}$

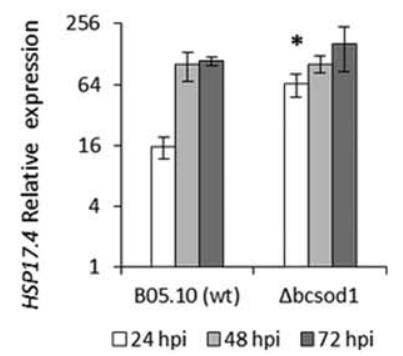

I

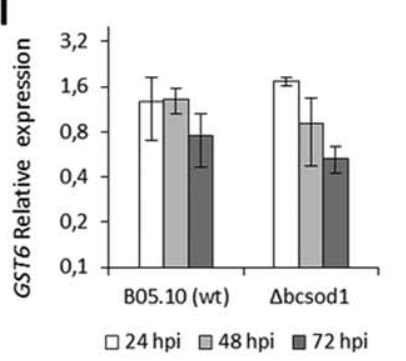

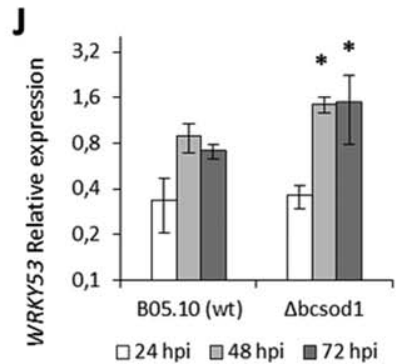

Fig. 7 Expression of the genes involved in signalling and in response to oxidative stress in Arabidopsis plants inoculated with $\Delta b c s o d 1$ or B05.10 (wild-type, WT). The relative expression of genes ICS1, PR1, PR2, PDF1.2, VSP1, HSP17.4, HSFA2, WRKY33, GST6 and WRKY53 was determined by real-time quantitative reverse transcription-polymerase chain reaction (RT-qPCR) in Arabidopsis plants infected with $\triangle$ bcsod1 or B05.10 at 24, 48 and 72 h post-inoculation (hpi) (A-J). EIF4A1 was used as an internal standard. Data are shown as the $\log _{2}$ fold change. Bars are the means of three independent experiments \pm standard deviation (SD). Asterisks indicate statistically significant differences between plants infected with B05.10 (WT) and $\Delta b c$ sod1 strains at each time point $(P<0.05$, unpaired $t$-test, two-tailed).

pathogen interaction is complex (Heller and Tudzynski, 2011). Both the plant and pathogen actively produce ROS during infection. ROS play a protective role and act as signalling compounds in plants (Muckenschnabel et al., 2001). Oxidative imbalance forms part of the plant defence response, but $B$. cinerea is also able to stimulate this mechanism for its own benefit (Finiti et al., 2014; Temme and Tudzynski, 2009).

In this article, we have demonstrated that the $\Delta b c s o d 1$ mutant shows significantly impaired virulence in Arabidopsis and tomato plants, as reported previously in French bean plants (Patel et al., 2008; Rolke et al., 2004). $\mathrm{H}_{2} \mathrm{O}_{2}$ accumulation decreased in Arabidopsis plants inoculated with $\Delta b c s o d 1$ versus WT (B05.10), whereas superoxide ion $\left(\mathrm{O}_{2}^{-}\right)$increased. The same alteration in ROS accumulation occurred in tomato plants inoculated with $\Delta$ bcsod1. Reduced $\mathrm{H}_{2} \mathrm{O}_{2}$ together with increased $\mathrm{O}_{2}^{-}$corresponds to a lack of SOD activity in the $\triangle b c s o d 1$ mutant, which catalyses the conversion of $\mathrm{O}_{2}^{-}$into $\mathrm{H}_{2} \mathrm{O}_{2}$ and $\mathrm{H}_{2} \mathrm{O}$. The reduced virulence and observed ROS imbalance could be caused by the inability of
$\Delta b c s o d 1$ to detoxify endogenous ROS and/or ROS from the host's oxidative burst in response to fungal infection. Although $\Delta b c s o d 1$ showed altered ROS production prior to infection, the nonrestoration of virulence by antioxidants indicates that sod 1 is not required to cope with the oxidative stress arising during host infection. Hence, BCSOD1 must play another role in the plantpathogen interaction. The lower infection rate of B05.10 in the presence of a reducing agent supports the notion that a necrotrophic fungus, such as $B$. cinerea, depends largely on direct (or indirect) ROS generation for host tissue colonization (Rolke et al,, 2004). The present work supports the contribution of BCSOD1 in the exploitation of the plant oxidative burst for the benefit of the pathogen. $\mathrm{BCSOD1}$ alters the $\mathrm{O}_{2}^{-} / \mathrm{H}_{2} \mathrm{O}_{2}$ rate, contributing to the $\mathrm{H}_{2} \mathrm{O}_{2}$ level, which damages plant tissue and reduces the activation of plant defence, increasing the susceptibility to $B$. cinerea.

Our results indicate that the $\mathrm{O}_{2}^{-} / \mathrm{H}_{2} \mathrm{O}_{2}$ imbalance produced in the absence of $b c s o d 1$ contributes to the $\mathrm{H}_{2} \mathrm{O}_{2}$ level, which signals and facilitates an efficient plant defence, which increases 

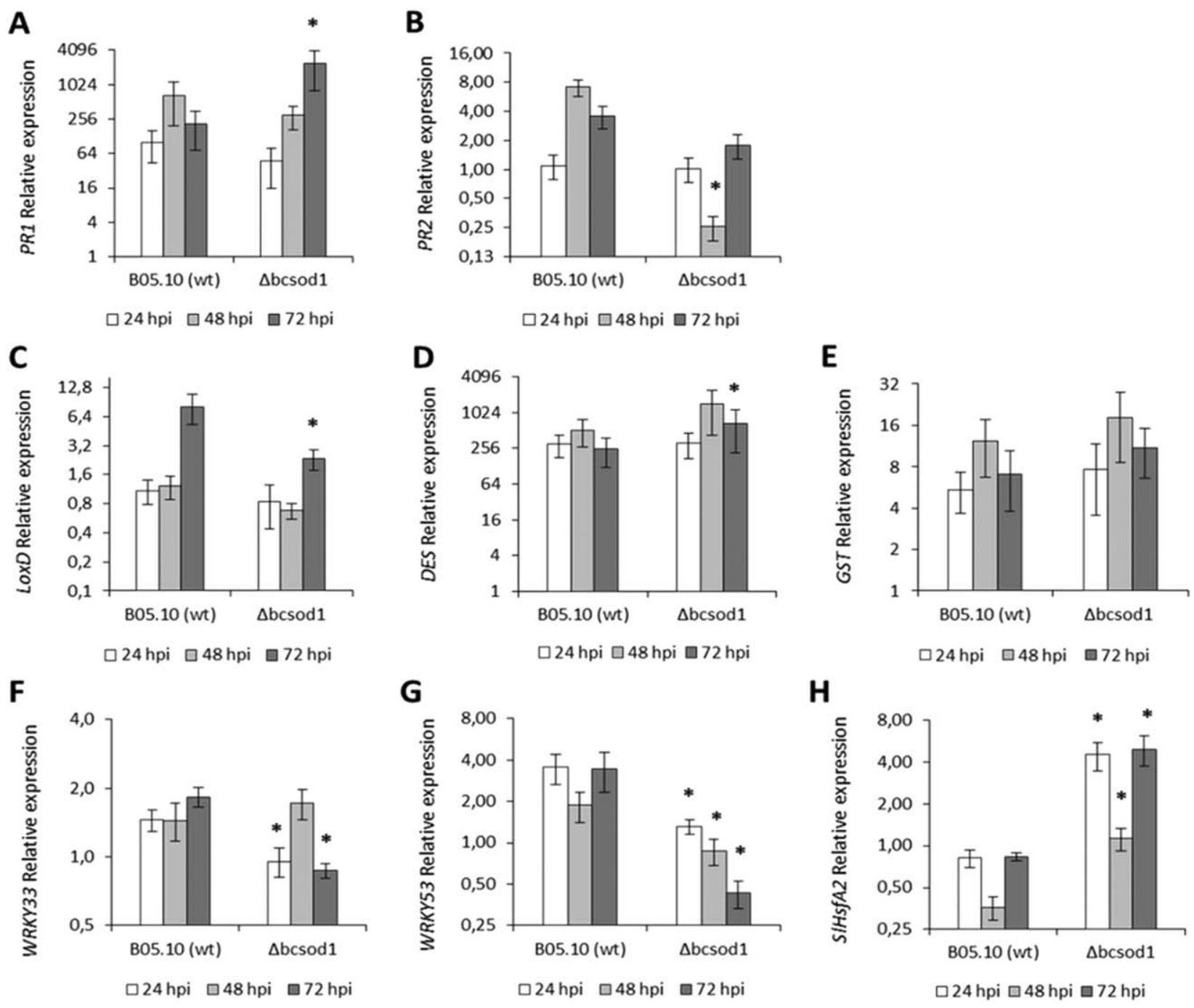

Fig. 8 Expression of the genes involved in signalling and in response to oxidative stress in tomato plants inoculated with $\Delta b c s o d 1$ or B05.10 (wild-type, WT). The relative expression of genes $P R 1, P R 2, L O X D, D E S, G S T, W R K Y 33$, WRKY53 and HSfA2 was determined by real-time quantitative reverse transcription-polymerase chain reaction (RT-qPCR) analysis in tomato plants infected with $\Delta$ bcsod1 or B05.10 at 24, 48 and $72 \mathrm{~h}$ post-inoculation (hpi) (A-H). EF1- $\alpha$ was used as an internal standard. Data are shown as the $\log _{2}$ fold change. Bars are the means of three independent experiments \pm standard deviation (SD). Asterisks indicate statistically significant differences between plants infected with B05.10 (WT) and $\Delta b c s o d 1$ strains at each time point $(P<0.05$, unpaired $t$-test, two-tailed).

resistance to $B$. cinerea. Hence, BCSOD1 constitutes a virulence factor. Some authors have suggested that the success or failure of certain pathogens depends on $\mathrm{H}_{2} \mathrm{O}_{2}$ accumulation (Govrin and Levine, 2000; Hückelhoven and Kogel, 2003; Kumar et al., 2001). Our previous data in tomato plants have shown a correlation between $\mathrm{H}_{2} \mathrm{O}_{2}$ accumulation and Botrytis susceptibility, which reflects the importance of the control of ROS accumulation in response to biotic stresses (Angulo et al., 2015; Finiti et al., 2014). The activation of more effective plant defences in the absence of sod1 supports this hypothesis. Heightened callose deposition occurs in plants following infection with $\Delta b c s o d 1$, depending on the transcriptional regulation of callose synthase. These data demonstrate the connection between changes in the $\mathrm{O}_{2}^{-} / \mathrm{H}_{2} \mathrm{O}_{2}$ ratio and defensive polysaccharide metabolism. A similar connection was shown by Vellosillo et al. (2010), where $\mathrm{O}_{2}^{-}$and singlet oxygen $\left({ }^{1} \mathrm{O}_{2}\right)$ induced a stronger accumulation of callose than did $\mathrm{H}_{2} \mathrm{O}_{2}$. We have reported previously the importance of callose deposition in the plant response to $B$. cinerea (Finiti et al., 2013; Flors et al., 2007; Vicedo et al., 2009). In $\Delta$ bcsod1-infected Arabidopsis and tomato plants, the callose core at the infection site increased. This callose core in the infection area was observed in Arabidopsis plants that overexpressed the callose synthase gene PMR4, leading to increased resistance to the adapted powdery mildew Golovinomyces cichoracearum and the non-adapted powdery mildew Blumeria graminis f. sp. hordei (Naumann et al., 2013). Recently, it has been proposed that callose itself is likely to act 
antagonistically on SA defence signalling, which is suggestive of the role of $P R 2$ as a modulator of callose- and SA-dependent defence responses (Oide et al., 2013). These authors showed that $A B A$ promotes callose deposition through the transcriptional repression of $P R 2$ in Arabidopsis challenged with Leptosphaeria maculans and Pseudomonas syringae. In our experimental system, callose acted as an antagonist of SA signalling in Arabidopsis and tomato plants. At the same time, the different regulation of $P R 2$ in both cultures could explain the distinct pattern of callose deposition on the border of the infection site in response to $\Delta b c s o d 1$. This could also be related to the higher susceptibility to B05.10 shown by tomato plants compared with Arabidopsis.

The absence of bcsod1 profoundly altered hormone signalling involved in plant basal responses. In Arabidopsis plants, both JAIle and OPDA signalling were activated. OPDA acts in a JAindependent manner by signalling to amino acid biosynthesis and cellular redox homeostasis in stress responses (Park et al., 2013). Sham et al. (2014) reported that Hsp17.4 is one of the genes commonly induced by $B$. cinerea infection, OPDA and oxidative stress in Arabidopsis. In tomato plants, the activation of OPDA signalling and the involvement of other oxylipins in plant protection against oxidative stress was observed, as shown previously (Angulo et al., 2015).

SA signalling was also activated on $\Delta b c s o d 1$ infection versus B05.10 in both cultures. This agrees with the concept that the effectiveness of plant responses against pathogens is much more complex than the classical antagonism between the SA and JA/ET pathways (Caarls et al., 2015; Grant and Jones, 2009). This also indicates that plant susceptibility relies on hormonal balance, which may differ depending on the culture. The key role of both callose and OPDA-mediated signalling in the plant response to Botrytis is noteworthy. In tomato, the silencing of OPR3 showed that OPDA alone plays a major role in basal defence against this necrotroph (Scalschi et al., 2015). In Arabidopsis, there is controversy with regard to whether OPDA promotes resistance to Alternaria brassicicola in the absence of $\mathrm{JA}$, because experimental conditions could mask the possible contribution of OPDA to pathogen resistance (Schilmiller et al., 2007; Stintzi et al., 2001). Our results strongly support the role of this oxylipin in the defence against Botrytis in both species. Previously, it has been shown that the oxylipins, which are formed by singlet oxygen, induce callose deposition (Vellosillo et al., 2010).

Our results also showed changes in WRKY53 and WRKY 33 in plants infected with $\Delta b c s o d 1$ versus B05.10. WRKY transcription factors control diverse processes, such as the response to pathogens or wounding, but also leaf senescence (Rushton et al., 2010). WRKY53 codes for a transcription factor that acts as a positive regulator of basal resistance, but also as a negative regulator of certain SA responses in Arabidopsis (Murray et al., 2007). Its induction is $\mathrm{H}_{2} \mathrm{O}_{2}$ dependent in Arabidopsis and tobacco plants
(Golemiec et al., 2014; Miao and Zentgraf, 2007), and the expression of a redox-sensitive transcription factor positively regulates age-induced leaf senescence (Xie et al., 2014). This gene is also involved in priming defence responses by epigenetic modifications (Jaskiewicz et al., 2011). In tomato, we have shown previously that the induction of the WRKY53 gene, which responds to Botrytis, is also primed by the natural inducer hexanoic acid on infection (Finiti et al., 2014). Recently, Van Eck et al. (2014) have demonstrated that the WRKY53 transcriptional network regulates oxidative responses to a wide array of stresses in rice.

WRKY33 plays a critical role in plant resistance to necrotrophic pathogens, including B. cinerea (Birkenbihl et al., 2012). The role of WRKY33 in Arabidopsis resistance to necrotrophic pathogens is linked to its positive role in the regulation of genes involved in the JA response and redox homeostasis (Birkenbihl et al., 2012).

In conclusion, although it is difficult to discriminate between fungal and plant contributions to ROS production, our results demonstrate that changes in ROS production, specifically $\mathrm{O}_{2}^{-} / \mathrm{H}_{2} \mathrm{O}_{2}$ imbalance, caused by the absence of fungal bcsod1, promote efficient defence responses, such as callose deposition, which are orchestrated by complex signalling crosstalk. This supports the hypothesis that SOD is important for the full virulence of Botrytis given its ability to produce $\mathrm{H}_{2} \mathrm{O}_{2}$ and exploit the plant oxidative burst, as suggested previously (Rolke et al., 2004; Tiedemann, 1997). Our data also support the notion that ROS play different roles in plants challenged by this necrotroph in accordance with the dynamics and specificity of ROS signalling and in networks with other signalling pathways, as reported previously in other systems (Mittler et al., 2011). The specific signalling roles of ROS need to be determined.

\section{EXPERIMENTAL PROCEDURES}

\section{Plant material, microbial strains and growth conditions}

Seeds of $A$. thaliana N70000 (WT) were pretreated at $4{ }^{\circ} \mathrm{C}$ in the dark for $48 \mathrm{~h}$ to synchronize germination. Plants were grown in Jiffy-7 pots (www. jiffygroup.com) in a growth chamber at $23{ }^{\circ} \mathrm{C}$ day/ $19{ }^{\circ} \mathrm{C}$ night, $8 \mathrm{~h}$ of light/day and $70 \%$ relative humidity (RH) for 5 weeks before being used. The N70000 ecotype was obtained from the Nottingham Arabidopsis Stock Centre (NASC) (http://Arabidopsis.info/). Tomato (Solanum lycopersicum) Cv. Ailsa Craig plants were grown in commercial peat in a glasshouse with $16 \mathrm{~h}$ of daylight. Tomato plants were grown for 4 weeks prior to use.

Botrytis cinerea strain B05.10 (WT) and mutant strain $\Delta b c s o d 1$ were kindly provided by Paul Tudzynski (University of Munster, Germany). Both strains were cultured on potato dextrose agar (PDA; Scharlau Microbiology, Sentmenat, Barcelona, Spain, 01-483-500) containing 0.5\% sucrose. The $\Delta$ bcsod1 strain was grown in the presence of hygromycin $(70 \mu \mathrm{g} / \mathrm{mL})$. Both strains were grown under dark conditions at $21^{\circ} \mathrm{C}$ with exposure to UV-A light (350-400 nm) for 15 min every $3 \mathrm{~h}$. 


\section{Botrytis cinerea challenge}

The spores of both strains were collected from 7-day-old cultures with sterile water that contained $0.02 \%(\mathrm{v} / \mathrm{v})$ Tween-20, which was then filtered, quantified with a haemocytometer and adjusted to the appropriate concentration. Prior to infection, spores were incubated in sterile water that contained 50\% (v/v) of supplemented Gambor's B5 medium (SigmaAldrich, St. Louis, MO, USA, Ref. G5893) for at least $2 \mathrm{~h}$. The spore density for infections in Arabidopsis plants was adjusted to $10^{5}$ spores $/ \mathrm{mL}$, and to $5 \times 10^{4}$ spores $/ \mathrm{mL}$ for infections in tomato plants. All the plants were inoculated with two drops $(5 \mu \mathrm{L})$ of conidial suspension per leaf (four leaves per plant in Arabidopsis and on the third and fourth leaves of tomato). Disease symptoms were assessed by determining the average necrotic lesion areas in leaves of living plants. All the experiments were performed with at least six plants.

\section{Hormone and metabolite analysis}

The extraction and quantification of hormones and metabolites were performed using an HPLC Waters Alliance 2690 (Milford, MA, USA) with a reverse phase column Nucleosil-ODS (100 mm $\times 2 \mathrm{~mm}$ i.d.; $5 \mu \mathrm{m}$ ) (Scharlab, Barcelona, Spain), as described in Vicedo et al. (2009). HPLC was coupled to a quadrupole-hexapole-quadrupole Quatro-LC (Micromass, Manchester, UK) mass spectrometer. Samples were obtained from leaves inoculated as described previously in living plants. The leaves at time $0 \mathrm{~h}$ and mock leaves were not infected. Quantitative data were processed by the Masslynx NT program, version 3.4 (Micromass; http://www.micromass.co.uk). Three replicate experiments were run with 12 plants per genotype/condition, and similar results were obtained.

\section{ROS quantification}

Leaves infected with both strains of $B$. cinerea were collected at 24,48 and $72 \mathrm{hpi}$ and were incubated with $\mathrm{DAB}$ for $8 \mathrm{~h}$ to view $\mathrm{H}_{2} \mathrm{O}_{2}$. For superoxide ion, leaves collected at the same time points were incubated in NBT for 2-3 h. Subsequently, samples were washed with $96 \%$ ethanol to remove chlorophyll and unbound stains. Samples were obtained from the leaves inoculated as described previously in living plants. Control leaves were not infected. $\mathrm{H}_{2} \mathrm{O}_{2}$ and superoxide ion accumulation were quantified with Gimp 2.6 software (http://www.gimp.org), and were expressed as the average number of brown pixels per million pixels and blue-grey pixels per million pixels, respectively, on digital photographs of infected leaf areas. For the production of $\mathrm{H}_{2} \mathrm{O}_{2}$ on microwell plates, strains were grown on PDA overlaid with cellophane for 3 days; $25 \mathrm{mg}$ of fresh mycelium was weighed and placed in $1 \mathrm{~mL}$ of fresh DAB solution $(0.5 \mathrm{mg}$ of DAB per millilitre); $8 \mathrm{~h}$ after incubation in the dark at room temperature, the resulting coloration was recorded photographically. For the negative control, $1 \mathrm{~mL}$ of DAB supplemented with $1 \mu \mathrm{L}$ of $\mathrm{H}_{2} \mathrm{O}_{2}(30 \%)$ was used and, for the positive control, $2 \mu \mathrm{L}$ of horseradish peroxidase (Sigma-Aldrich, P8375) and $1 \mu \mathrm{L}$ of $\mathrm{H}_{2} \mathrm{O}_{2}(30 \%)$ were added to $1 \mathrm{~mL}$ of DAB. For superoxide ion accumulation in the hyphae of both $B$. cinerea strains, drops of 20 $\mu \mathrm{L}$, which contained $10^{5}$ spores $/ \mathrm{mL}$, were placed on the surface of a slide and were germinated in a moist chamber overnight. Samples were stained by applying a drop of $20 \mu \mathrm{L}$ of NBT $(0.05 \% \mathrm{w} / \mathrm{v})$, and were monitored and photographed by microscopy $2 \mathrm{~h}$ after staining. As a control, $20 \mu \mathrm{L}$ of DPI ( $50 \mu \mathrm{m}$; diphenyleneiodonium chloride, Sigma, St. Louis, MO, USA, D2926) were added to some of the samples. For in planta infection assay with AA or DTT of $\Delta b c s o d 1$ and WT, conidial suspensions of $10^{5}$ spores $/ \mathrm{mL}$ were supplemented with $5 \mathrm{~g}$ of AA per litre or $750 \mu \mathrm{m}$ of DTT prior to inoculation. Quantification of the necrotic lesion area was examined at $72 \mathrm{hpi}$. The assays were repeated three times with at least six plants per genotype/condition, and similar results were obtained.

\section{Callose deposition}

Callose was determined by aniline blue staining, as described by Flors et al. (2007). Samples were obtained from leaves inoculated as described previously in living plants. Control leaves were not infected. The quantification of infected areas was performed by digital image analysis, and by calculation of the number of fluorescent pixels per million pixels with Gimp 2.6 software. The assay was repeated three times with at least six plants per genotype/condition, and similar results were obtained.

\section{Analysis of gene expression by RT-qPCR}

Total RNA was extracted from samples obtained from leaves inoculated as described previously in living plants with the NucleoSpin RNA Plant kit (Macherey-Nagel GmbH, Düren, Germany \& Co; Ref. 740949.50). RNA quantification was performed using a NanoDrop ND1000, Thermo Scientific, Wilmington, DE, USA. CDNA was obtained as described by Finiti et al. (2013). Relative quantification was used to determine the differential expression of genes. Arabidopsis EIF4A1 and tomato EF1- $\alpha$ were employed as internal reference. The relative expression was determined by the $\Delta \Delta \mathrm{Ct}$ method (Pfaffl, 2001); data are shown on a logarithmic scale base 2 . Real-time efficiency $(E)$ was calculated for each primer pair according to the equation: $E=10[-1 / \mathrm{slope}]$. Three replicates were performed with at least six plants per genotype/condition, and similar results were obtained. The genes and primers used for the Arabidopsis and tomato analyses are reported in Table S1 (see Supporting Information).

\section{Statistical analysis}

Differences between groups were calculated with Student's $t$-test $(P<0.05$, unpaired $t$-test, two-tailed). All the experiments were repeated three times with a minimum of six plants for each genotype/condition per experiment. The values shown are the means of the independent biological replicates \pm standard deviation (SD).

\section{ACKNOWLEDGEMENTS}

This work was supported by grants from the Spanish Ministry of Science and Innovation (AGL2010-22300-C03-01-02 and AGL2013-49023-C0301-02), co-funded by the European Regional Development Funds (ERDF) and by Generalitat Valenciana Grupos de Excelencia PROMETEO/2012/ 066. J.L.-C. and O.C.-S. were recipients of research contracts from the PROMETEO/2012/066 grant. E.F.-C. was the recipient of research contracts from grant AGL2010-22300-C03-01. J.L.-C. is the recipient of a research contract from grant AGL2013-49023-C03-01. We thank Dr Paul Tudzynski for providing the $\Delta b c s o d 1$ strain and for critical reading of the manuscript. We thank the SCSIE (Servicio Central de Soporte a la Investigación Experimental) Greenhause section (University of Valencia) for technical support. We also thank Helen Warburton for English editing. 


\section{REFERENCES}

Angulo, C., Leyva, M.O., Finiti, I., López-Cruz, J., Fernández-Crespo, E., GarcíaAgustín, P., González-Bosch, C. (2015) Role of dioxygenase $\alpha$-DOX2 and SA in basal response and in hexanoic acid-induced resistance of tomato (Solanum lycopersicum) plants against Botrytis cinerea. J. Plant Physiol. 175, 163-173.

Asselbergh, B., de Vleesschauwer, D. and Höfte, M. (2008) Abscisic acid deficiency leads to rapid activation of tomato defence responses upon infection with Erwinia chrysanthemi. Mol. Plant Pathol. 9, 11-24.

Beckers, G.J.M. and Spoel, S.H. (2006) Fine-tuning plant defense signalling: salicylate versus jasmonate. Plant Biol. 8, 1-10.

Birkenbihl, R.P., Diezel, C. and Somssich, I.E. (2012) Arabidopsis WRKY33 is a key transcriptional regulator of hormonal and metabolic responses toward Botrytis cinerea infection. Plant Physiol. 159, 266-285.

Caarls, L., Pieterse, C.M. and Van Wees, S.C. (2015) How salicylic acid takes transcriptional control over jasmonic acid signaling. Front. Plant Sci. 6, 170.

Donofrio, N.M. and Delaney, T.P. (2001). Abnormal callose response phenotype and hypersusceptibility to Peronospoara parasitica in defence-compromised Arabidopsis nim1-1 and salicylate hydroxylase-expressing plants. Mol. Plant-Microbe Interact. 14, 439-450.

El Oirdi, M., El Rahman, T.A., Rigano, L., El Hadrami, A., Rodriguez, M.C., Daayf, F., Vojnov, A. and Bouarab, K. (2011) Botrytis cinerea manipulates the antagonistic effects between immune pathways to promote disease development in tomato. Plant Cell, 23, 2405-2421.

Ellinger, D., Naumann, M., Falter, C., Zwikowics, C., Jamrow, T., Manisseri, C., Somerville, S.C. and Voigt, C.A. (2013) Elevated early callose deposition results in complete penetration resistance to powdery mildew in Arabidopsis. Plant Physiol. 161, 1433-1444.

Finiti, I., Leyva, M.O., López-Cruz, J., Calderan Rodrigues, B., Vicedo, B., Angulo, C., Bennett, A.B., Grant, M., García-Agustín, P. and GonzálezBosch, C. (2013) Functional analysis of endo-1,4- $\beta$-glucanases in response to Botrytis cinerea and Pseudomonas syringae reveals their involvement in plantpathogen interactions. Plant Biol. 15, 819-831.

Finiti, I., Leyva, M.0., Vicedo, B., Gómez-Pastor, R., López-Cruz, J., GarcíaAgustín, P., Real, M.D. and González-Bosch, C. (2014) Hexanoic acid protects tomato plants against Botrytis cinerea by priming defence responses and reducing oxidative stress. Mol. Plant Pathol. 15, 550-562.

Flors, V., Leyva, M.O., Vicedo, B., Finiti, I., Real, M.D., García-Agustín, P., Bennett, A.B. and González-Bosch, C. (2007) Absence of the endo- $\beta-1,4-$ glucanases Cel1 and Cel2 reduces susceptibility to Botrytis cinerea in tomato. Plant J. 52, 1027-1040.

de Gara, L., de Pinto, M.C. and Tommasi, F. (2003). The antioxidant systems vis àvis reactive oxygen species during plant-pathogen interaction. Plant Physiol. Biochem. 41, 863-870

Glazebrook, J. (2005). Contrasting mechanisms of defense against biotrophic and necrotrophic pathogens. Annu. Rev. Phytopathol. 43, 205-227.

Golemiec, E., Tokarz, K., Wielanek, M. and Niewiadomska, E. (2014). A dissection of the effects of ethylene, $\mathrm{H}_{2} \mathrm{O}_{2}$ and high irradiance on antioxidants and several genes associated with stress and senescence in tobacco leaves. J. Plant Physiol. 171, 269-275.

Govrin, E.M. and Levine, A. (2000). The hypersensitive response facilitates plant infection by necrotrophic pathogen Botrytis cinerea. Curr. Biol. 10, 751-757.

Grant, M.R. and Jones, J.D. (2009). Hormone (dis)harmony moulds plant health and disease. Science, 324, 750-752.

Hauck, P., Thilmony, R. and He, S.Y. (2003). A Pseudomonas syringae type III effector suppresses cell wall-based extracellular defense in susceptible Arabidopsis plants. Proc. Natl. Acad. Sci. USA, 100, 8577-8582.

Heller, J. and Tudzynsky, P. (2011). Reactive oxygen species in phytopathogenic fungi: signaling, development and disease. Annu. Rev. Phytopathol. 49, 369390.

Hückelhoven, R. and Kogel, K.H. (2003) Reactive oxygen intermediates in plantmicrobe interactions: who is who in powdery mildew resistance? Planta, 216, 891-902

Itoh, A. and Howe, G.A. (2001) Molecular cloning of a divinyl ether synthase. Identification as a CYP74 cytochrome P-450. J. Biol. Chem. 276, 3620-3627.

Jaskiewicz, M., Conrath, U. and Peterhänsel, C. (2011) Chromatin modification acts as a memory for systemic acquired resistance in the plant stress response. EMBO Rep. 12, 50-55.

Kumar, J., Hückelhoven, R., Beckhove, U., Nagarajan, S. and Kogel, K.H. (2001) A compromised Mlo pathway affects the response of barley to the necrotrophic fungus Bipolaris sorokiniana (Teleomorph: Cochliobolus sativus) and its toxins. Phytopathology, 1, 127-133.

Masuda, S., Tokaji, Y., Kobayashi, Y. and Ohta, H. (2014). Mechanisms of induction of the stress-responsive transcription factors HsfA2 and DREB2A by 12 oxophytodienoic acid in Arabidopsis thaliana. Biosci. Biotechnol. Biochem. 78 647-650.

Miao, Y. and Zentgraf, U. (2007). The antagonist function of Arabidopsis WRKY53 and ESR/ESP in leaf senescence is modulated by the jasmonic and salicylic acid equilibrium. Plant Cell, 19, 819-830.

Mittler, R., Vanderauwera, S., Suzuki, N., Miller, G., Tognetti, V.B., Vandepoele, K., Gollery, M., Shulaev, V. and Van Breusegem, F. (2011) ROS signaling: the new wave? Trends Plant Sci. 16, 300-309.

Muckenschnabel, I., Williamson, B., Goodman, B.A., Lyon, G.D., Stewart, D. and Deighton, N. (2001) Markers for oxidative stress associated with soft rots in French beans (Phaseolus vulgaris) infected by Botrytis cinerea. Planta, 212, 376 381.

Murray, S.L., Ingle, R.A., Petersen, L.N. and Denby, K.J. (2007) Basal resistance against Pseudomonas syringae in Arabidopsis involves WRKY53 and a protein with homology to a nematode resistance protein. Mol. Plant-Microbe Interact. 20, 1431-1438.

Naumann, M., Somerville, S.C. and Voigt, C.A. (2013) Differences in early callose deposition during adapted and non-adapted powdery mildew infection of resistant Arabidopsis lines. Plant Signal. Behav. 8, 1-4

Oide, S., Bejai, S., Staal, J., Guan, N., Kaliff, M. and Dixelius, C. (2013) A novel role of $P R 2$ in abscisic acid (ABA) mediated, pathogen-induced callose deposition in Arabidopsis thaliana. New Phytol. 200, 1187-1199.

Park, S.W., Li, W., Viehhauser, A., He, B., Kim, S., Nilsson, A.K., Andersson, M.X., Kittle, J.D., Ambavaram, M.M., Luan, S., Esker, A.R., Tholl, D., Cimini, D., Ellerström, M., Coaker, G., Mitchell, T.K., Pereira, A., Dietz, K.J. and Lawrence, C.B. (2013) Cyclophilin 20-3 relays a 12-oxo-phytodienoic acid signal during stress responsive regulation of cellular redox homeostasis. Proc. Natl. Acad. Sci. USA, 110, 9559-9564.

Patel, R.M., van Kan, J.A.L., Bailey, A.M. and Foster, G.D. (2008) RNA-mediated gene silencing of superoxide dismutase (bcsod1) in Botrytis cinerea. Phytopathology, 98, 1134-1139.

Pfaffl, M.W. (2001) A new mathematical model for relative quantification in realtime RT-PCR. Nucleic Acids Res. 29, e45.

Pieterse, C.M.J., Leon-Reyes, A., Van der Ent, S. and Van Wees, S.C.M. (2009) Networking by small-molecule hormones in plant immunity. Nat. Chem. Biol. 5, 308-316.

Robert-Seilaniantz, A., Grant, M. and Jones, J.D. (2011). Hormone crosstalk in plant disease and defense: more than just jasmonate-salicylate antagonism. Annu. Rev. Phytopathol. 49, 317-343.

Rolke, Y., Liu, S., Quidde, T., Williamson, B., Schouten, A., Weltring, K.M., Siewers, V., Tenberge, K.B., Tudzynski, B. and Tudzynski, P. (2004) Functional analysis of $\mathrm{H}_{2} \mathrm{O}_{2}$ generating systems in Botrytis cinerea: the major $\mathrm{Cu}-\mathrm{Zn}$ superoxide dismutase (BCSOD1) contributes to virulence on French bean, whereas a glucose oxidase (BCGOD1) is dispensable. Mol. Plant Pathol. 5, 17-27.

Ryals, J.A., Neuenschwander, U.H., Willits, M.G., Molina, A., Steiner, H.Y. and Hunt, M.D. (1996). Systemic acquired resistance. Plant Cell, 8, 1809-1819.

Rushton, P.J., Somssich, I.E., Ringler, P. and Shen, Q.J. (2010) WRKY transcription factors. Trends Plant Sci. 15, 247-258.

Scalschi, L., Sanmartín, M., Camañes, G., Troncho, P., Sánchez-Serrano, J.J., García-Agustín, P., Vicedo, B. (2015) Silencing of OPR3 in tomato reveals the role of OPDA in callose deposition during the activation of defense responses against Botrytis cinerea. Plant J. 81, 304-315.

Schilmiller, A.L., Koo, A.J. and Howe, G.A. (2007) Functional diversification of acyl-coenzyme A oxidases in jasmonic acid biosynthesis and action. Plant Physiol. $143,812-824$.

Sham, A., Al-Azzawi, A., Al-Ameri, S., Al-Mahmoud, B., Awwad, F., AlRawashdeh, A., Iratni, R. and AbuQamar, S. (2014) Transcriptome analysis reveals genes commonly induced by Botrytis cinerea infection, cold, drought and oxidative stresses in Arabidopsis. PLoS One, 9, e113718.

Smart, M.G., Aist, J.R. and Israel, H.W. (1986). Structure and function of wall appositions 2. Callose and the resistance of oversize papillae to penetration by Erysiphe graminis sp. hordei. Can. J. Bot. 64, 802-804.

Soylu, S., Brown, I. and Mansfield, J.W. (2005). Cellular reactions in Arabidopsis following challenge by strains of Pseudomonas syringae: from basal resistance to compatibility. Physiol. Mol. Plant Pathol. 66, 232-243. 
Stintzi, A., Weber, H., Reymond, P., Browse, J. and Farmer, E.E. (2001) Plant defense in the absence of jasmonic acid: the role of cyclopentenones. Proc. Natl. Acad. Sci. USA, 98, $12837-12842$.

Tiedemann, A.V. (1997). Evidence for a primary role of active oxygen species in induction of host cell death during infection of bean leaves with Botrytis cinerea. Physiol. Mol. Plant Pathol. 50, 151-166.

Temme, N. and Tudzynski, P. (2009). Does Botrytis cinerea ignore $\mathrm{H}_{2} \mathrm{O}_{2}$-induced oxidative stress during infection? Characterization of Botrytis activator protein 1. Mol. Plant-Microbe Interact. 22, 987-998.

Van Eck, L., Davidson, R.M., Wu, S., Zhao, B.Y., Botha, A.M., Leach, J.E. and Lapitan, N.L. (2014). The transcriptional network of WRKY53 in cereals links oxidative responses to biotic and abiotic stress inputs. Funct. Integr. Genomics, 14, 351-362.

Vellosillo, T., Vicente, J., Kulasekaran, S., Hamberg, M. and Castresana, C. (2010). Emerging complexity in reactive oxygen species production and signaling during the response of plants to pathogens. Plant Physiol. 154, 444-448.

Vicedo, B., Flors, V., Leyva, M.O., Finiti, I., Kravchuk, Z., Real, M.D., GarcíaAgustín, P. and González-Bosch, C. (2009) Hexanoic acid-induced resistance against Botrytis cinerea in tomato plants. Mol. Plant-Microbe Interact. 22, 1455-1465.

Viefhues, A., Heller, J., Temme, N. and Tudzynski, P. (2014) Redox systems in Botrytis cinerea: impact on development and virulence. Mol. Plant-Microbe Interact. 27, 858-874
Voigt, CA. (2014) Callose-mediated resistance to pathogenic intruders in plant defense-related papillae. Front. Plant Sci. 5, 168.

Williamson, B., Tudzynski, B., Tudzynski, P., van Kan, JA. (2007) Botrytis cinerea: the cause of grey mould disease. Mol. Plant Pathol. 8, 561-580.

Xie, Y., Huhn, K., Brandt, R., Potschin, M., Bieker, S., Straub, D., Doll, J., Drechsler, T., Zentgraf, U. and Wenkel, S. (2014) REVOLUTA and WRKY53 connect early and late leaf development in Arabidopsis. Development, 141, 47724783.

Zimmerli, L., Stein, M., Lipka, V., Schulze-Lefert, P. and Somerville, S. (2004) Host and non-host pathogens elicit different jasmonate/ethylene responses in Arabidopsis. Plant J. 40, 633-646.

\section{SUPPORTING INFORMATION}

Additional Supporting Information may be found in the online version of this article at the publisher's web-site:

Table S1 Primers used for reverse transcription quantitative polymerase chain reaction (RT-qPCR). 